\title{
Postinvasive Bacterial Resistance Conferred by Open Stomata in Rice
}

\author{
Dandan Zhang, ${ }^{1,2}$ Caijuan Tian, ${ }^{1}$ Kangquan Yin, ${ }^{1}$ Wenyi Wang, ${ }^{1}$ and Jin-Long Qiu ${ }^{1,+}$ \\ ${ }^{1}$ State Key Laboratory of Plant Genomics, Institute of Microbiology, Chinese Academy of Sciences, Beijing 100101, China; and \\ ${ }^{2}$ University of Chinese Academy of Sciences, Beijing 100049, China
}

Accepted 16 August 2018.

\begin{abstract}
Stomata are leaf pores that regulate gas exchange and water transpiration in response to environmental cues. They also function in innate immunity by limiting pathogen entry through actively closing in so-called stomatal defense. However, roles of stomata in plant disease resistance are not fully elucidated, especially in monocots. Here, we report that non-race specific resistance of the rice abscisic acid-deficient mutant Osabal to Xanthomonas oryzae pv. oryzae is due to increased stomatal conductance. Reducing stomatal conductance in the Osabal mutant increases its susceptibility to $X$. oryzae pv. oryzae. Artificial opening of stomata in wild-type plants leads to enhanced resistance to $X$. oryzae pv. oryzae. The rice mutant es 1-1 with constitutively higher stomatal conductance exhibits strong resistance to $X$. oryzae pv. oryzae. Additionally, Osabal and $e$ 1-1 are resistant to $X$. oryzae pv. oryzicola. The data support that open stomata confer postinvasive resistance against bacterial pathogens in rice, and such resistance probably results from decreased leaf water potential. Our findings reveal a novel role of stomata in plant immunity through modulation of leaf water status, which provides physiological insight into the interactions between plant, pathogen, and environment.
\end{abstract}

Bacterial pathogens cause major crop diseases worldwide (Bashan 1987). On the other hand, plants combat invading pathogens with a layered immune system, including immunity

\section{Zhang and C. Tian contributed equally to this work.}

The sequence data in this article can be found in the Rice Genome Annotation Project website or GenBank/EMBL database under the following accession numbers: OsABA1 (OsZEP, LOC_Os04g37619), OsABA2 (OsSDR, LOC_Os03g59610), OsABA3(OsMoCo, LOC_Os06g45860), OsABA8ox1 (LOC_Os02g47470), OsActin1 (LOC_Os03g50885), OsWRKY13 (LOC_Os01g54600), OsPR-1a (LOC_Os07g03710), nahG (M60055.1) OsNPR1 (LOC_Os01g09800), and OsUBQ5 (LOC_Os01g22490).

The author(s) declare there is no conflict of interest.

${ }^{\dagger}$ Corresponding author: Jin-Long Qiu; E-mail: qiujl@im.ac.cn

Funding: This work was supported by grants from the Strategic Priority Research Program of the Chinese Academy of Sciences (XDB11030500), the National Key Research and Development Program of China (2016YFD0100602), and the National Natural Science Foundation of China (31071673 and 31371929).

*The $\boldsymbol{e}$-Xtra logo stands for "electronic extra" and indicates that one supplementary table and five supplementary figures are published online.

○ 2019 The American Phytopathological Society triggered by perception of conserved, microbe-associated molecular patterns (MAMPs) or by direct or indirect recognition of bacterial effectors deployed as virulence factors (Jones and Dangl 2006; Sanabria et al. 2008). Successful infection also depends on the ability of a pathogen to modulate the physiology of the host to favor pathogen multiplication and colonization (Beattie and Lindow 1999; Le Fevre et al. 2015; Xin et al. 2016). However, the cellular and physiological details of plant-bacterial pathogen interactions remain, to a great extent, unclear. For example, how do adapted pathogenic bacteria acquire nutrients and water from plants, and how do the bacteria grow and spread in plant tissues (Fatima and Senthil-Kumar 2015)? Understanding of these mechanisms might lead to novel strategies to enhance plant defenses against pathogenic bacteria.

After host recognition, most foliar bacterial pathogens must enter leaf tissue to obtain nutrients and water for multiplication and establish substantial infective populations (Melotto et al. 2008). These bacteria get into host tissue typically through wounds or natural openings on the leaf surface such as hydathodes and stomata (Lindow and Brandl 2003). Stomata are pores formed by pairs of guard cells on leaves (Underwood et al. 2007). Stomata function in innate immunity by actively closing to limit pathogen entry. This so-called stomatal defense is triggered by MAMPs (Melotto et al. 2006, 2017). In turn, bacterial pathogens have evolved virulence factors that suppress stomatal closure to facilitate their entry and colonization of host tissues (Lozano-Durán et al. 2014; Melotto et al. 2006).

Stomata control gas exchange between the atmosphere and leaves that is required for photosynthesis. Additionally, stomata mediate transpiration, which drives water transport from root to shoot and, finally, evaporation from leaves (Underwood et al. 2007). Therefore, stomata play a major role in plantenvironment interactions (Zhu et al. 2012). Consistently, stomatal conductance changes in response to various abiotic and biotic stimuli such as drought, light, and microbial infection. Plants have evolved complicated mechanisms to control stomatal opening and closure to balance interior water homeostasis and carbon dioxide intake for survival and optimal growth (Chavarria and dos Santos 2012). The phytohormone abscisic acid (ABA) is a major regulator of stomatal closure. Varieties of abiotic stress induce ABA biosynthesis, which results in stomatal closure and prevents plant water loss (Tuteja 2007). Recently, ABA emerged as an important regulator of plant immunity (Asselbergh et al. 2008; Cao et al. 2011). Clearly, understanding the interactions between environmental cues and the immune system is a prerequisite for successful plant disease management (Webb et al. 2010). Most details of the interplay between abiotic and biotic defense pathways remain elusive. Although it appears that ABA plays an essential role in this (Cao et al. 2011), its mode of action is just beginning 
to be understood. Therefore, it is worthwhile to investigate whether adjustment of stomatal conductance plays a role in this process.

Transpiration mediated by stomata leads to water loss from leaves. One key function of stomata is to control leaf water status (Chavarria and dos Santos 2012). It is not surprising that foliar bacterial pathogens and plants battle for water during their interactions (Beattie 2016). Water soaking is commonly observed on leaves in the infiltration site of bacterial pathogens (Reimers and Leach 1991). After infiltration into leaves, only compatible pathogenic bacteria managed to establish large populations, whereas nonpathogenic and incompatible bacterial strains showed very little growth (Wilson et al. 1999). However, high humidity and continued water soaking of leaves promote the growth of both pathogenic and nonpathogenic foliar bacteria (Xin et al. 2016; Young 1974). It appears that bacterial pathogens are able to modify the leaf interior environment for successful colonization by, in part, modulating host water status (Beattie 2011; Beattie and Lindow 1995). Bacterial effectors such as HopM1 in Pseudomonas syringae and AvrHah1 in Xanthomonas gardneri enable apoplast hydration (Schornack et al. 2008; Xin et al. 2016). On the other hand, plants actively reduce fluid movement and promote water loss in host cells undergoing effector-triggered immunity (ETI), suggesting that plants possess a counter-defense against modulation of host water status by bacterial pathogens. This idea is supported by the fact that high humidity is able to suppress host hypersensitive cell death induced by ETI (Freeman and Beattie 2009). Despite progress on understanding how bacterial pathogens establish the host interior aqueous environment, the action mode and physiological basis of host control of water status against pathogens remain elusive.

Rice (Oryza sativa) is one of the most important staple crops worldwide and is also a popular model monocot (Bajaj and Mohanty 2005). Bacterial leaf blight (BLB) caused by $X$. oryzae pv. oryzae is one of the most destructive diseases of rice (Zhang and Wang 2013), and the rice- $X$. oryzae pv. oryzae system is an excellent model for studying host-pathogen interactions (Chen and Ronald 2011; Niño-Liu et al. 2006). Here, we show that rice mutants with constitutively open stomata exhibit strong resistance to BLB. In addition, artificial opening of stomata led to enhanced resistance to $X$. oryzae pv. oryzae. This resistance resulted from decreased water potential in these stomata-open plants.

\section{RESULTS}

\section{Rice Osaba1 mutant exhibits}

\section{non-race specific resistance to blight bacteria.}

A genetic screen in japonica rice ( $O$. sativa 'Nipponbare') identified a mutant exhibiting strong resistance to $X$. oryzae pv. oryzae, here called Osabal. Leaves of Osabal were inoculated with the virulent $X$. oryzae pv. oryzae strain PXO99 by the leaftip clipping method (Fig. 1A). In this way, the pathogen gained access to the vascular system via wounds, multiplied in the host, and spread systemically through the xylem; thus, lesion length was an indicator of disease development (Kauffman et al. 1973; Noda and Kaku 1999). The Osabal mutant displayed strong resistance to $X$. oryzae pv. oryzae. The average lesion formed on wild-type leaves 12 days after inoculation was approximately $10 \mathrm{~cm}$ in length whereas, on the mutant, it was only approximately $3 \mathrm{~cm}$ (Fig. 1A). We further tested several other virulent $X$. oryzae pv. oryzae strains (PXO61, PXO86, PXO71, PXO112, PXO145, and Zhe173), and Osabal exhibited strong resistance to all these strains (Fig. 1B). This indicates that the Osabal mutant exhibits non-race specific resistance to bacterial blight pathogens.
Map-based analysis of 534 individuals with a $X$. oryzae pv. oryzae-resistant phenotype from a segregating F2 population derived from a cross between Osabal and Minghui 63 indica variety located the mutation to a region on chromosome 4 between markers S4-19.8 and S4-23. Genome sequencing of this region revealed a G-to-T substitution in OsZEP or OsABAI (LOC_Os04g37619) gene in the mutant (Fig. 1C). To further verify the identity of $O S A B A 1$ locus, a binary vector carrying full-length OsABA1 cDNA was transformed into Osabal mutants. The transgenic progeny exhibited restored $X$. oryzae pv. oryzae susceptibility of the Osabal mutant to the level of wildtype plants (Fig. 1D). These results indicate that the $X$. oryzae pv. oryzae resistance phenotype of the Osabal mutant is due to mutation in the OsZEP or OsABAl gene.

When grown in a paddy field, the Osabal mutant displayed a lesion mimic phenotype. Small reddish-brown lesions were scattered over the leaves exposed to sunlight at the tillering stage (Supplementary Fig. S1). In contrast, no lesions were visible on Osabal leaves when they were grown in a controlled growth chamber under a cycle of $13 \mathrm{~h}$ of light at $28^{\circ} \mathrm{C}$ and $11 \mathrm{~h}$ of darkness at $26^{\circ} \mathrm{C}$, and this was further confirmed by trypan blue staining of the leaves. Osabal mutants grown in growth chambers still exhibited strong resistance to $X$. oryzae pv. oryzae, suggesting that their resistance is independent of the lesion-mimic phenotype. In order to avoid the effect of the lesion-mimic phenotype of Osabal mutants on our work, all of the following experiments were performed with plants grown in a controlled-growth chamber.

\section{Decreased ABA content leads}

to $X$. oryzae pv. oryzae resistance in rice.

The G-to-T mutation in the Osabal mutant converts Arg424 to Ile in zeaxanthin epoxidase (ZEP), a key enzyme in ABA biosynthesis, resulting in extremely low ABA content (Fig. 1E). To confirm that $X$. oryzae pv. oryzae resistance in Osabal is caused by OsZEP/OsABA1 dysfunction, we sprayed exogenous ABA on Osabal seedlings to see whether this would reverse the resistance phenotype. Indeed, the ABA-treated mutant plants became susceptible to $X$. oryzae pv. oryzae, and their susceptibility increased with increasing concentrations of ABA such that, ultimately, there was no difference in lesion lengths induced in the wild type or mutants sprayed with $100 \mu \mathrm{M} \mathrm{ABA}$ (Fig. 1F). These data point to a direct role of $\mathrm{ABA}$ in the disease resistance of the Osabal mutant.

To further investigate whether ABA deficiency leads to $X$. oryzae pv. oryzae resistance, we generated transgenic plants expressing RNAi for the ABA biosynthesis genes OsABA2 and $O s A B A 3$, and plants overexpressing the ABA catabolic gene OsABA8oxl (Fang and Chu 2008; Saika et al. 2007). Expression levels of these transgenes were analyzed by reversetranscription polymerase chain reaction (RT-PCR), and representative lines were chosen for further inoculation experiments with PXO99. Disease lesions formed on these transgenic lines were significantly shorter than on the wild type (Fig. $1 \mathrm{G}$ and $\mathrm{H})$. These results reveal that suppression of ABA biosynthesis genes and overexpression of an ABA catabolic gene lead to $X$. oryzae pv. oryzae resistance in rice.

\section{X. oryzae pv. oryzae resistance in Osabal is due} to increased stomatal conductance and transpiration rate.

ABA has been proposed to enhance the susceptibility of rice to $X$. oryzae pv. oryzae and Magnaporthe grisea by attenuating salicylic acid (SA) signaling (Jiang et al. 2010; Xu et al. 2013; Yazawa et al. 2012). However, the basal level of SA is high in rice and pathogen infections do not significantly change its level in local or systemic leaves (Silverman et al. 1995). We found that transcript levels of the SA signaling marker genes 

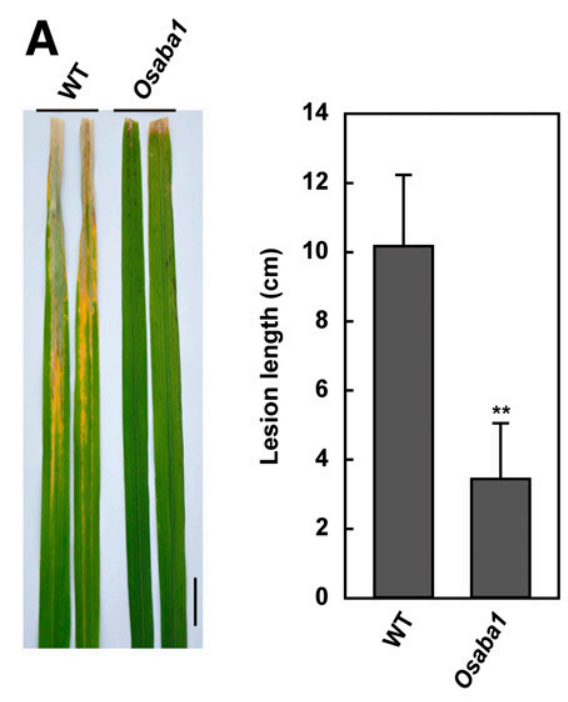

B

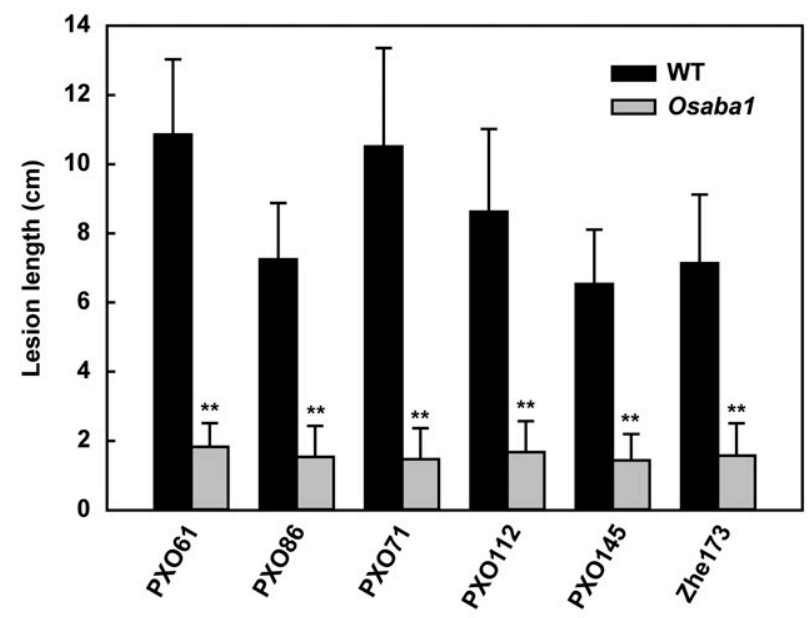

C

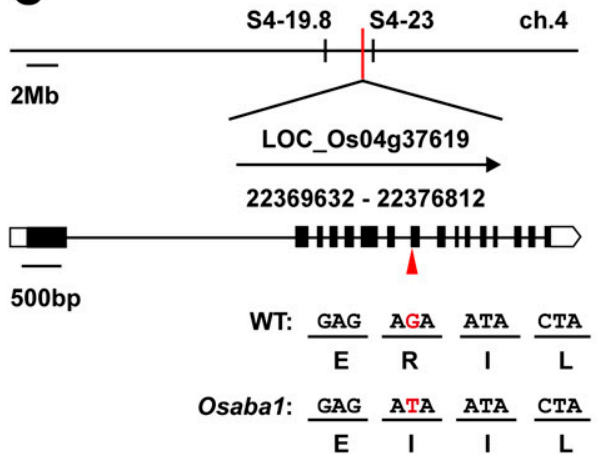

D

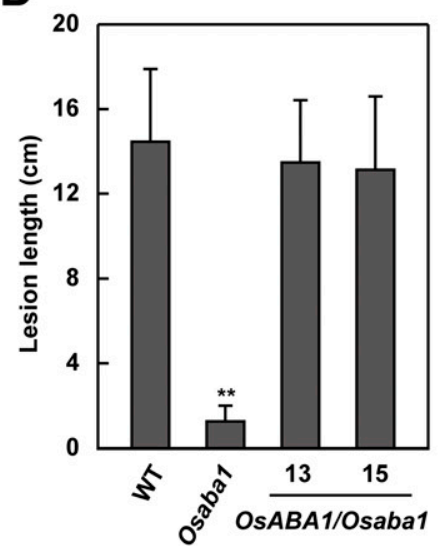

E
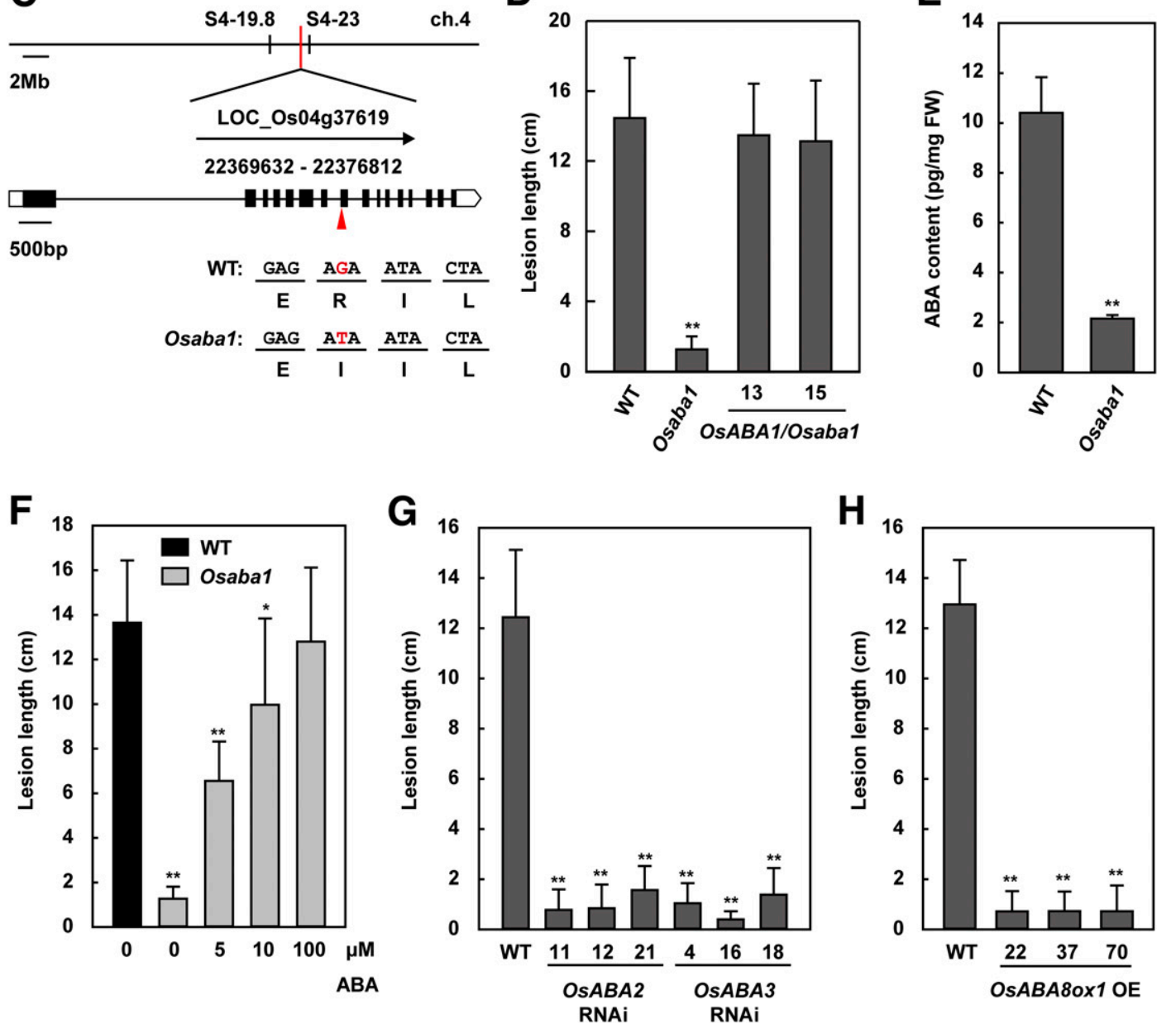

Fig. 1. Abscisic acid (ABA) deficiency in rice leads to strong resistance to bacterial leaf blight. A, Disease lesion development on leaves of wild-type (WT) plants and the Osabal mutant 12 days after leaf-clip inoculation with Xanthomonas oryzae pv. oryzae strain PXO99. Lesion lengths were measured and analyzed (right panel). Photographs of representative leaves are shown in the left panel. Bar $=1 \mathrm{~cm}$. B, Lesion lengths measured 12 days after leaf-clip inoculation with indicated X. oryzae pv. oryzae strains. C, Map-based cloning of Osabal. The locus was mapped to a region between marker S4-19.8 and marker S4-23 of chromosome 4. The exon (closed rectangle) and intron (line) organization of the OsABA1 gene is illustrated, and the position of the Osabal mutation (a G-to-T mutation converts Arg424 to Ile) is indicated by an arrow. D, Lesion lengths of WT plants, Osabal, and Osabal plants transformed with OsABA1 (OsABA1/Osabal) were measured and analyzed at 12 days postinoculation (dpi). E, ABA content of WT and Osabal plants. FW = fresh weight. F, Exogenous ABA restores the susceptibility of the Osabal mutant to X. oryzae pv. oryzae. Rice plants were pretreated by spraying with ABA at the indicated concentrations 1 day before $X$. oryzae pv. oryzae inoculation, and lesion lengths were measured at $12 \mathrm{dpi}$. G, Lesion lengths were measured on leaves of the $O s A B A 2$ and $O s A B A 3$ RNAi lines at $12 \mathrm{dpi}$. H, Lesion lengths were measured on the leaves of the OsABA8oxl-overexpressing lines at 12 dpi. Values are means \pm standard deviation, $n \geq 8$, and $*$ and $* *$ indicate $P<0.05$ and 0.01 , respectively ( $t$ test). 
OsWRKY13 and OsPR-1a were comparable in the Osabal mutant and wild-type Nipponbare plants (Supplementary Fig. S2), indicating that SA signaling is not activated by ABA deficiency. Similar results were previously obtained in rice treated with fluridone, an inhibitor of ABA biosynthesis (Xu et al. 2013). Interestingly, expression of $O s P R-1 a$ was still induced by $X$. oryzae pv. oryzae infection in the Osabal mutant, even to a higher level than in wild-type plants. To further investigate the role of SA in Osabal X. oryzae pv. oryzae resistance, we introduced the bacterial salicylate hydroxylase gene $n a h G$ into Osabal by crossing with a rice transgenic line (Tang et al. 2011). As expected, the SA level in the Osabal/nahG plants was greatly reduced. Resistance to PXO99 was not compromised in the Osabal/nahG plants, even though nahG plants are more susceptible to PXO99 than wild-type plants. Similarly, RNAi for $O S N P R 1$, a key component of the SA signaling, did not affect $X$. oryzae pv. oryzae resistance of Osabal mutants. Together, these observations indicate that SA plays a role in rice disease resistance but that the resistance of Osabal to $X$. oryzae pv. oryzae is largely independent of SA.

ABA regulates stomatal closure and, thereby, controls transpiration and leaf water status (Kim et al. 2010; Mittelheuser and Van Steveninck 1969). The Osabal mutant loses water faster than the wild type (Fig. 2A), and its stomatal conductance and transpiration rate are greatly elevated (Fig. 2B), in agreement with the idea that ABA deficiency leads to larger steadystate stomatal opening (Merilo et al. 2018). To test whether the resistance of Osabal to $X$. oryzae pv. oryzae is due to the increased stomatal opening, we checked its disease resistance after treating leaves with antitranspirant and chemicals or environmental cues that induce stomatal closure or opening. Because long-term treatments may damage leaves, we examined $X$. oryzae pv. oryzae infection just 3 or 4 days postinoculation (dpi). To facilitate observation of $X$. oryzae $\mathrm{pv}$. oryzae migration inside rice leaves, we used an enhanced green fluorescent protein (EGFP) tagged X. oryzae pv. oryzae, PXO99 ${ }_{\text {EGFP, }}$ which exhibits virulence similar to that of PXO99 (Han et al. 2008) (Supplementary Fig. S3). Disease development was quantified by measurement of $X$. oryzae pv. oryzae migration in rice leaves with microscopic observation of the fluorescence of PXO99 ${ }_{\mathrm{EGFP}}$

Wilt-Pruf (terpene oligomers) is a film-forming antitranspirant. After spraying on leaf surfaces, Wilt-Pruf spray dries to form a clear, transparent, and flexible protective coating that seals the stomata and prevents transpiration (Walters 2006). As expected, stomatal conductance and transpiration rate were greatly decreased in Wilt-Pruf-treated wild-type and Osabal plants (Fig. 2C). Importantly, Wilt-Pruf treatment largely restored the susceptibility of Osabal to X. oryzae pv. oryzae (Fig. 2D), indicating a link between stomatal conductance and disease resistance against $X$. oryzae pv. oryzae. Similarly, when Osabal mutants were exposed to $100 \mu \mathrm{M}$ atrazine (2-chloro-4-ethylamino6-isopropylamino-s-triazine), a herbicide which closes stomata and inhibits transpiration (Jachetta et al. 1986; Powles and $\mathrm{Yu}$ 2010), their stomatal conductance and transpiration rate declined (Fig. 2E), and they became more susceptible to $X$. oryzae pv. oryzae (Fig. 2F). These data support an important role of open stomata in the $X$. oryzae pv. oryzae resistance of Osabal mutants.

\section{Incremental increases in stomatal conductance and transpiration rate leads \\ to $X$. oryzae pv. oryzae resistance in rice.}

We further checked whether manipulation of stomatal opening affected the resistance of rice to $X$. oryzae pv. oryzae. Each stoma is composed of a pair of guard cells, and stomatal opening is caused by swelling of the guard cells due to accumulation of potassium salts (Sun et al. 2014). The fungal toxin fusicoccin stimulates potassium uptake by guard cells and causes stomatal opening (Kinoshita et al. 2001; Turner 1972). When leaves of wild-type Nipponbare were sprayed with $10 \mu \mathrm{M}$ fusicoccin, stomatal conductance and transpiration rate increased dramatically (Fig. 3A) and the plants exhibited increased resistance to $X$. oryzae pv. oryzae (Fig. 3B).

We next investigated the effect of environmental cueinduced stomatal opening on disease resistance. Stomata close in the dark and open in the light (Zeiger 1983). Wild-type plants were inoculated with $X$. oryzae pv. oryzae and half of the inoculated plants were placed under continuous light, while the other half were grown under $13 \mathrm{~h}$ of light and $11 \mathrm{~h}$ of darkness. Plants illuminated continuously were more resistant to $X$. oryzae pv. oryzae, forming significantly shorter disease lesions (Fig. 3C). This result further supports the idea that open stomata confer $X$. oryzae pv. oryzae resistance in rice. In agreement with this, treatment of wild-type rice leaves with Wilt-Pruf led to enhanced susceptibility to $X$. oryzae pv. oryzae (Fig. 2D).

\section{The rice mutant $e$ s 1-1 with constitutively higher stomatal conductance exhibits strong resistance to $X$. oryzae pv. oryzae.}

The role of stomatal conductance and transpiration rate in disease resistance was further explored with a genetic approach. The rice mutant es $1-1$, harboring a mutation in LOC_ Os01g11040, resulted in loss of function of OsSCAR2. Stomatal conductance and transpiration rate were significantly higher in the es1-1 mutant (Fig. 3D), due to higher stomatal density and increased number of semiopen stomata under steady state (Rao et al. 2015). Intriguingly, this mutant also displayed strong resistance to $X$. oryzae pv. oryzae (Fig. 3E), and Wilt-Pruf treatment could partially rescue the resistance phenotype of the mutant (Fig. 3F). This result provides additional evidence for an essential role of stomatal opening in rice disease resistance.

\section{Water status affects rice resistance against bacterial blight.}

$X$. oryzae pv. oryzae enters the rice leaf through wounds when inoculated by the clipping method, then spreads via the xylem (Noda and Kaku 1999). Therefore, it seems that stomata opening does not directly affect rice defense against the bacterial pathogen. Stomata opening increases transpiration rate (Figs. 2 and 3) and, thereby, decreases water availability in the leaf interior (Xu and Zhou 2008). Because water status in leaf tissues greatly affects growth and infection of bacterial pathogens (Beattie 2011; Xin et al. 2016), stomatal opening may modulate host water status to confer resistance against $X$. oryzae pv. oryzae in rice. Therefore, we measured water potential, an indicator of water status, in rice leaves. Water potential in the Osabal mutants was approximately $-1.6 \mathrm{MPa}$, much lower than in wild-type rice plants (approximately -1.0 $\mathrm{MPa}$ ) (Fig. 4A).

Ambient humidity can directly affect plant water status via stomata. To confirm that altered water status in Osabal leads to enhanced $X$. oryzae pv. oryzae resistance, we shifted plants at day 0 postinoculation from conditions of regular $(50 \%$ relative humidity) to high ( $90 \%$ relative humidity) humidity. The susceptibility of Osabal to $X$. oryzae pv. oryzae was largely restored by growing under high-humidity conditions (Fig. 4B). Interestingly, wild-type plants grown under high humidity also exhibit slightly increased susceptibility to $X$. oryzae pv. oryzae (Fig. 4B). These data support a role of leaf water status in rice resistance against bacterial blight. 
A

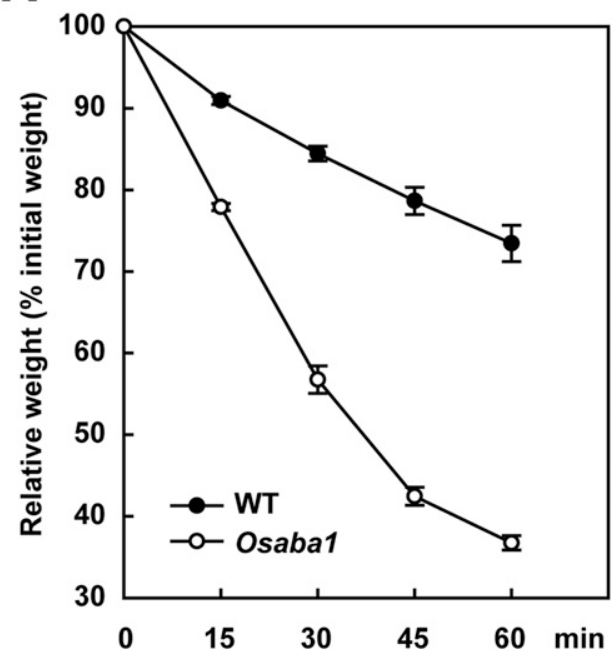

B

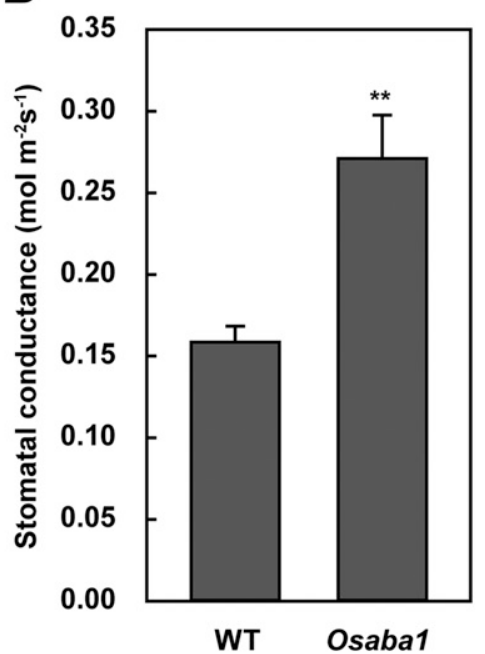

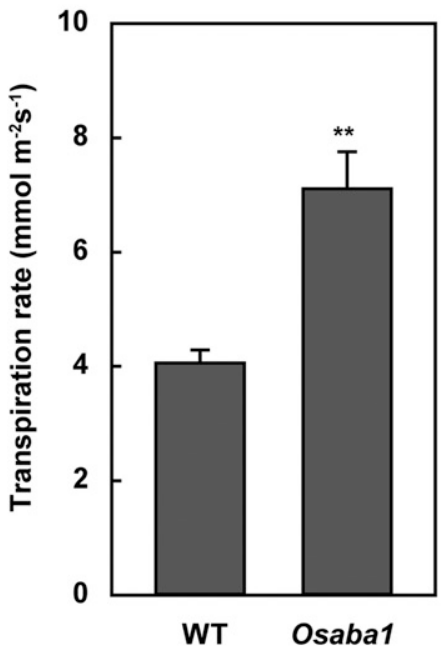

D

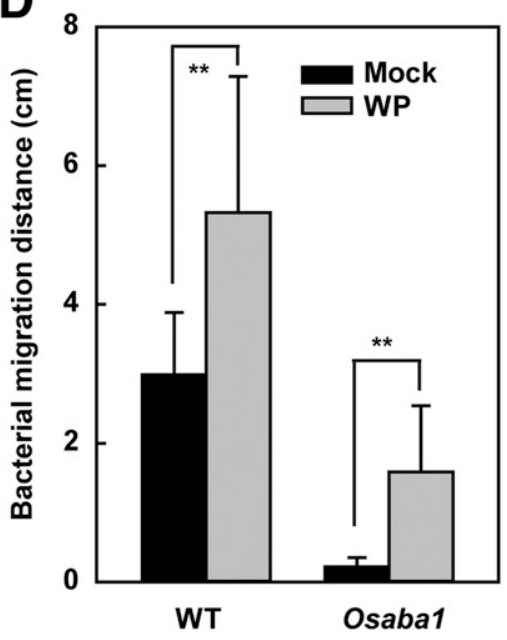

$\mathbf{F}$

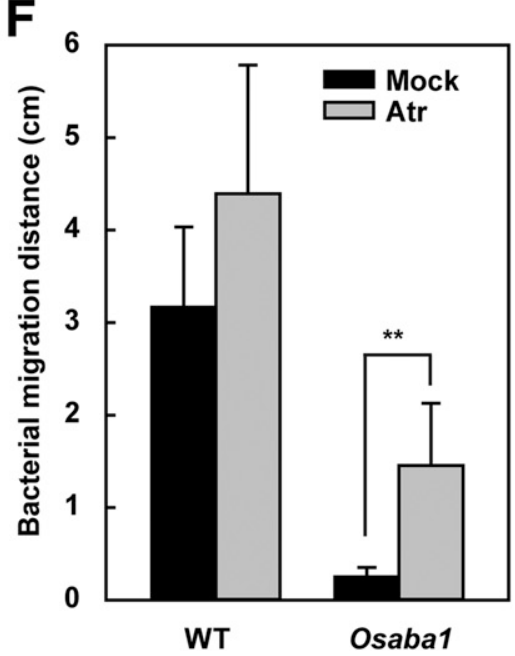

Fig. 2. Role of stomatal opening in the resistance of Osabal to bacterial leaf blight. A, Water loss from detached leaves of wild-type (WT) and Osabal plants. A kinetic analysis of water loss was performed, and results are shown as percentages of the initial fresh weights at each time point. B, Stomatal conductance and transpiration rate of WT and Osabal rice leaves measured with an LI-6400XT portable photosynthesis system. C, Treatment with the antitranspirant Wilt-Pruf decreases stomatal conductance and transpiration rate of WT and Osabal leaves. Plants were sprayed with water (mock) or Wilt-Pruf (WP), and measurements made 24 h later. D, Migration distances of PXO99 $9_{\mathrm{EGFP}}$ on rice leaves 3 days post leaf-clip inoculation. WT and Osaba1 plants were inoculated with PXO99 $9_{\mathrm{EGFP}}$ 1 day after Wilt-Pruf treatment. Bacterial migration was visualized under a fluorescence microscope with green fluorescent protein (GFP) fluorescence in the veins. E, Stomatal conductance and transpiration rate of WT and Osabal plants 1 day after treatment with $100 \mu \mathrm{M}$ atrazine (Atr). F, Migration distances of PXO99 EGFP $_{\text {on rice leaves measured } 3 \text { days post leaf-clip inoculation. WT and Osabal plants were inoculated with PXO99 }}$ EGFP 1 day after Atr treatment. Values are means \pm standard deviation, $n \geq 6$, and asterisks $(* *)$ indicate $P<0.01$ ( $t$ test). 
Both multiplication and spread of leaf-infiltrated $X$. oryzae pv. oryzae are compromised in the Osabal mutant.

To examine how the infection of $X$. oryzae pv. oryzae is affected in Osabal, we infiltrated PXO99 $9_{\text {EGFP }}$ into leaves. Multiplication and spread of the bacteria was measured by quantification of $X$. oryzae pv. oryzae in contiguous, 3-cm-long leaf segments at and around the infiltration site (Fig. 5A). In Osabal, the population of $X$. oryzae pv. oryzae was slightly reduced at the infiltration site but greatly decreased in adjacent leaf segments, and no bacteria could be detected in leaf segments $3 \mathrm{~cm}$ further away (Fig. 5A). Confocal imaging of cross-sections of leaf segments (segment B) adjacent to the infiltration site revealed that the fluorescence of PXO99 ${ }_{\mathrm{EGFP}}$ was only present in the xylem of wild-type plants but not of the Osabal mutant, whereas the fluorescence was observed in the intercellular spaces of both wide-type and mutant leaves (Fig. 5B). This indicates that $X$. oryzae pv. oryzae fails to colonize the xylem of the Osabal mutant. Consistently, $8 \mathrm{dpi}$, necrotic lesions spread in both directions from the infiltration site in the wild-type leaves but were restricted to a small region around the infiltration site in Osabal (Fig. 5C). Together, these results indicate that multiplication and spread of leaf-infiltrated $X$. oryzae pv. oryzae are compromised in the Osabal mutant.

\section{The Osabal and $e s 1-1$ mutants are resistant} to leaf streak bacteria.

$X$. oryzae pv. oryzicola, a nonvascular bacterial pathogen causing rice bacterial leaf streak, infects leaves through stomata and colonizes intercellular spaces of the parenchyma, finally resulting in necrotic lesions between the veins (NiñoLiu et al. 2006). To test whether the resistance in the Osabal mutant is limited to vascular pathogens such as $X$. oryzae pv. oryzae, we infiltrated $X$. oryzae pv. oryzicola into the rice leaves. The Osabal mutant also exhibited strong resistance to $X$. oryzae pv. oryzicola (Fig. 5D). Similarly, the rice mutant
A

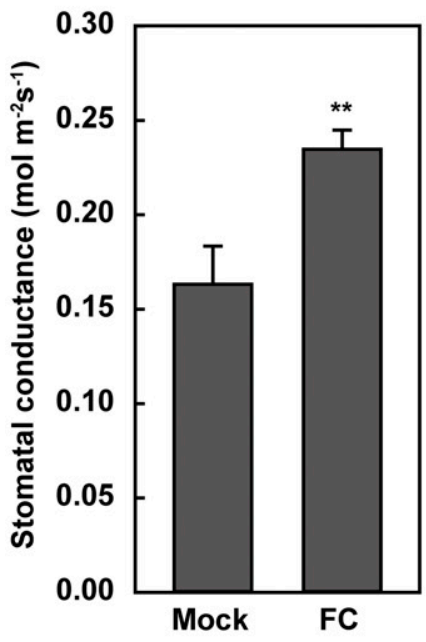

B

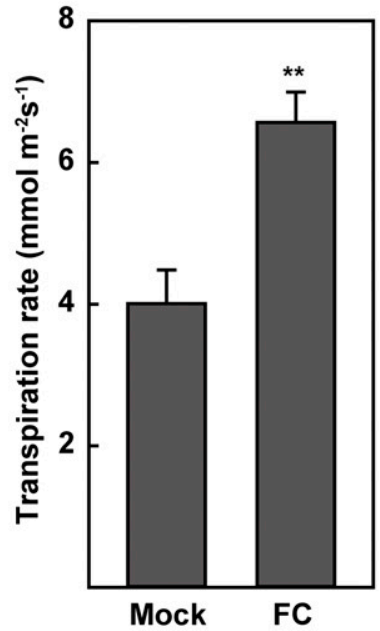

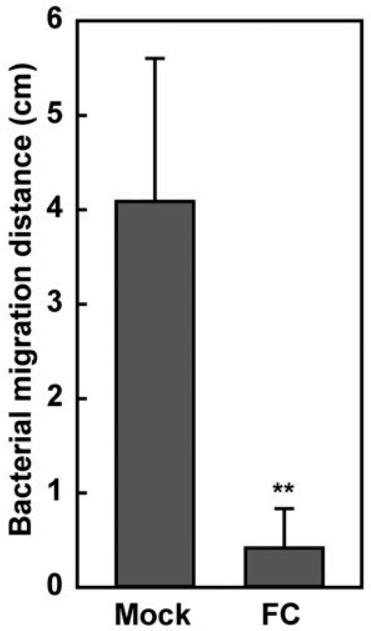

C

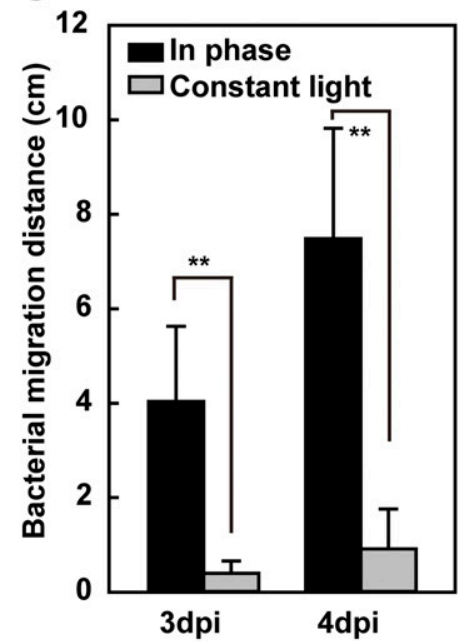

D

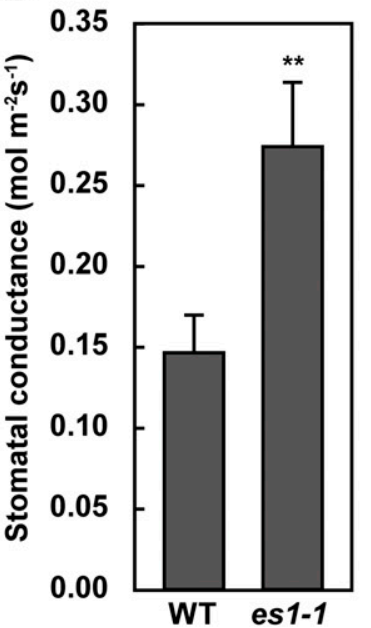

E

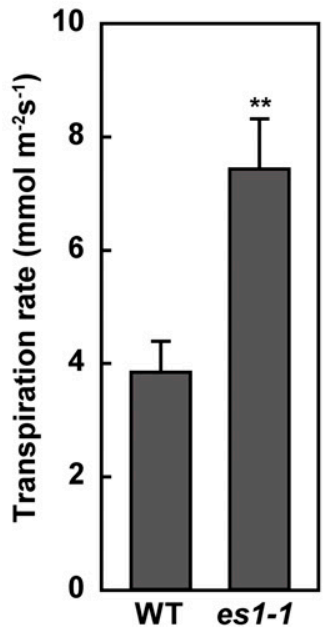

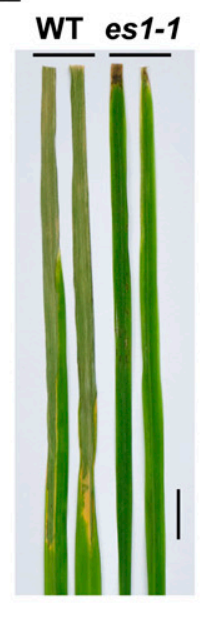
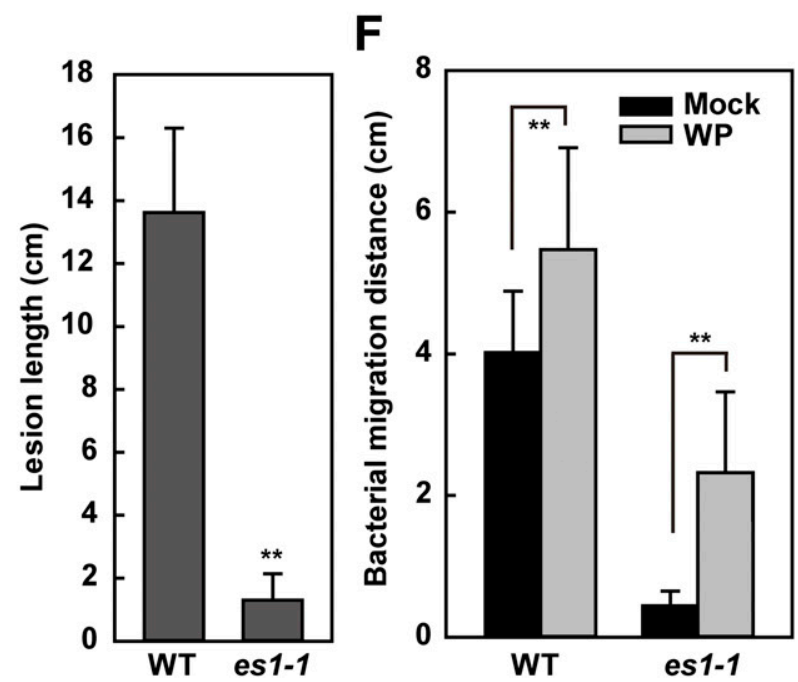

Fig. 3. Opening of stomata increases the resistance of rice against bacterial leaf blight. A, Stomatal conductance and transpiration rate of wild-type (WT) plants

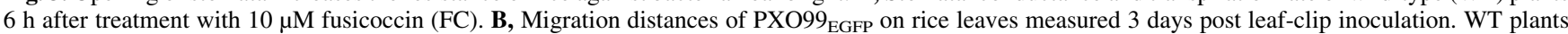
were inoculated with PXO99 ${ }_{\mathrm{EGFP}} 6 \mathrm{~h}$ after FC treatment. C, Migration distances of PXO99 ${ }_{\mathrm{EGFP}}$ on rice leaves measured 3 and 4 days post leaf-clip inoculation. After inoculation, WT plants were maintained in a growth chamber either with constant light or with a cycle (in phase) of $13 \mathrm{~h}$ of light and $11 \mathrm{~h}$ of darkness. $\mathbf{D}$, Stomatal conductance and transpiration rate of WT and es 1-1 mutant rice leaves. E, The es 1-1 mutant is highly resistant to X. oryzae pv. oryzae. Disease lesion lengths were measured 12 days post leaf-clip inoculation with PXO99. Photographs of representative leaves are shown in the right panel. Bar = $1 \mathrm{~cm}$. F, WiltPruf treatment partially rescues the resistance phenotype of the es $1-1$ mutant. Plants were leaf-clip inoculated with PXO99 $9_{\mathrm{EGFP}} 1$ day after Wilt-Pruf treatment, and distances migrated by the bacteria were measured at 3 days postinoculation. Values are means \pm standard deviation, $n \geq 8$, and asterisks ( $* *$ ) indicate $P<$ 0.01 ( $t$ test). 
es 1-1 also showed strong $X$. oryzae pv. oryzicola resistance (Supplementary Fig. S4). Because X. oryzae pv. oryzicola infects rice via stomata, we also spray inoculated $X$. oryzae pv. oryzicola on leaves of wild-type and Osabal mutant plants. Osabal again exhibited enhanced resistance to $X$. oryzae pv. oryzicola (Fig. 5E). Together, these results suggest that open stomata confer postinvasive resistance to bacterial pathogens.

\section{Rice leaf water status changes}

upon $X$. oryzae pv. oryzae infection.

It is possible that $X$. oryzae pv. oryzae is able to modulate stomatal conductance in rice leaves. To examine this, we inoculated wild-type rice plants with $X$. oryzae pv. oryzae by leaf clipping. At 3 dpi, a disease lesion was visible around the inoculation site of the leaf and, at $4 \mathrm{dpi}$, the lesion spread from the tip of the leaf (Supplementary Fig. S5). In order to avoid effects of the disease lesion, we measured the stomatal conductance and transpiration rate at $3 \mathrm{dpi}$. Both stomatal conductance and transpiration rate were greatly reduced in the infected leaves (Fig. 6A). This result indicates that $X$. oryzae pv. oryzae infection can induce host stomatal closure. Interestingly, the ABA content was also induced by $X$. oryzae pv. oryzae infection (Fig. $6 \mathrm{~B})$, suggesting that $X$. oryzae pv. oryzae-induced stomata closure may be due to increased ABA levels.

Water-soaked lesions are an early symptom of rice bacterial blight. We observed that water soaking appeared around the infiltration areas in wild-type leaves $1 \mathrm{dpi}$. This water soaking became darker and extended along veins in both directions from the infiltration sites as the disease developed (Fig. 6C). In contrast, water soaking was barely detectable in Osabal mutants at infiltration sites and also spread much more slowly (Fig. 6C). Next, we quantified the leaf interior water potential by introducing into $X$. oryzae pv. oryzae the water-potential reporter proU-inaZ fusion (Wright and Beattie 2004). In wildtype plants, water potentials sensed by $X$. oryzae pv. oryzae increased from $-1.26 \mathrm{MPa}$ at 1 dpi to $-0.92 \mathrm{MPa}$ at $3 \mathrm{dpi}$, whereas it only slightly increased in the Osabal mutant (Fig. $6 \mathrm{D})$. Together, these data support the idea that $X$. oryzae pv. oryzae infection modulates host leaf water status.

\section{DISCUSSION}

Understanding the physiological processes by which plants defend against bacterial pathogens is a prerequisite for crop disease management. Stomata are natural openings on plant leaves which open and close in response to various extracellular and intracellular stimuli. A major function of stomata is to regulate gas exchange and water transpiration. In this work, we found that open stomata in rice lead to resistance to leaf blight bacteria, and this resistance is conferred through modulation of host water status. Stomata conductance and water status are affected by environmental cues such as light, drought, and humidity (Schulze and Hall 1982). In addition, environmental conditions affect the outcome of host-pathogen interactions (Scholthof 2007). Our findings offer new insight into the interactions between plant, pathogens, and environment.

The phytohormone ABA modulates the interplay between responses to abiotic and biotic stresses. However, the effects of ABA on plant disease resistance are not fully understood (Cao et al. 2011; De Vleesschauwer et al. 2013). We found that ABA negatively regulates the defense of rice to $X$. oryzae pv. oryzae (Fig. 1) because the ABA-deficient Osabal rice mutant exhibited strong resistance to $X$. oryzae pv. oryzae. SA also plays a role in rice disease resistance (Xu et al. 2013). Exogenous treatment of rice leaves with ABA promoted plant susceptibility to pathogens, probably by antagonizing SA

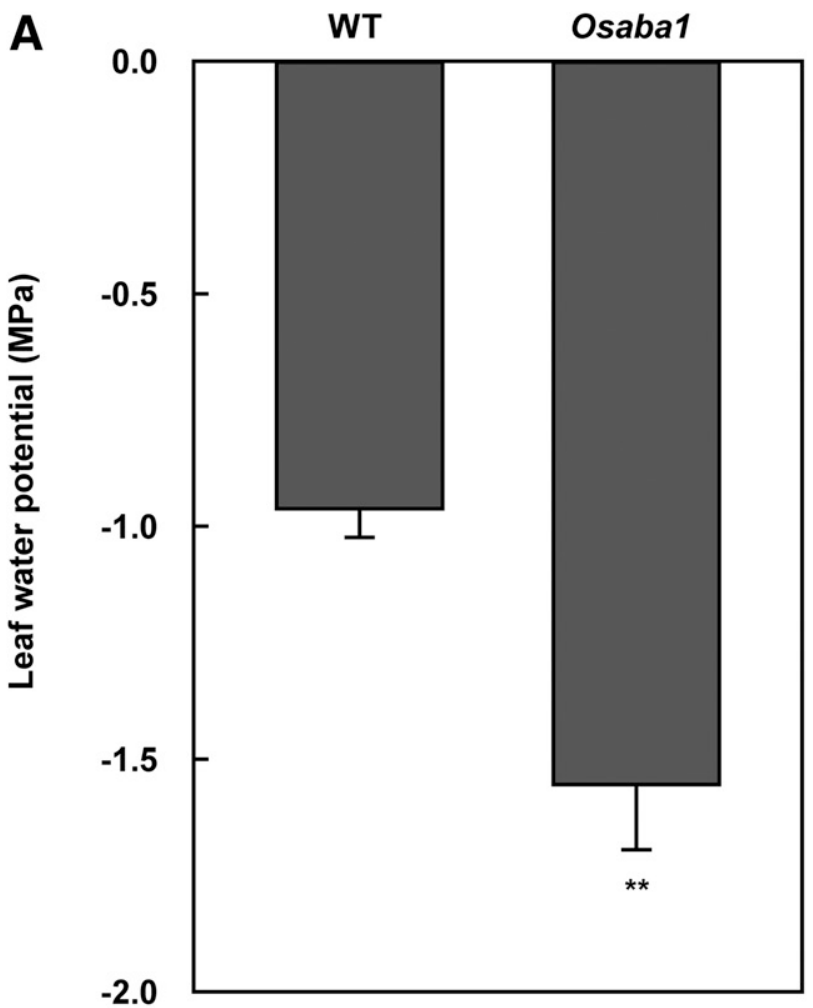

B

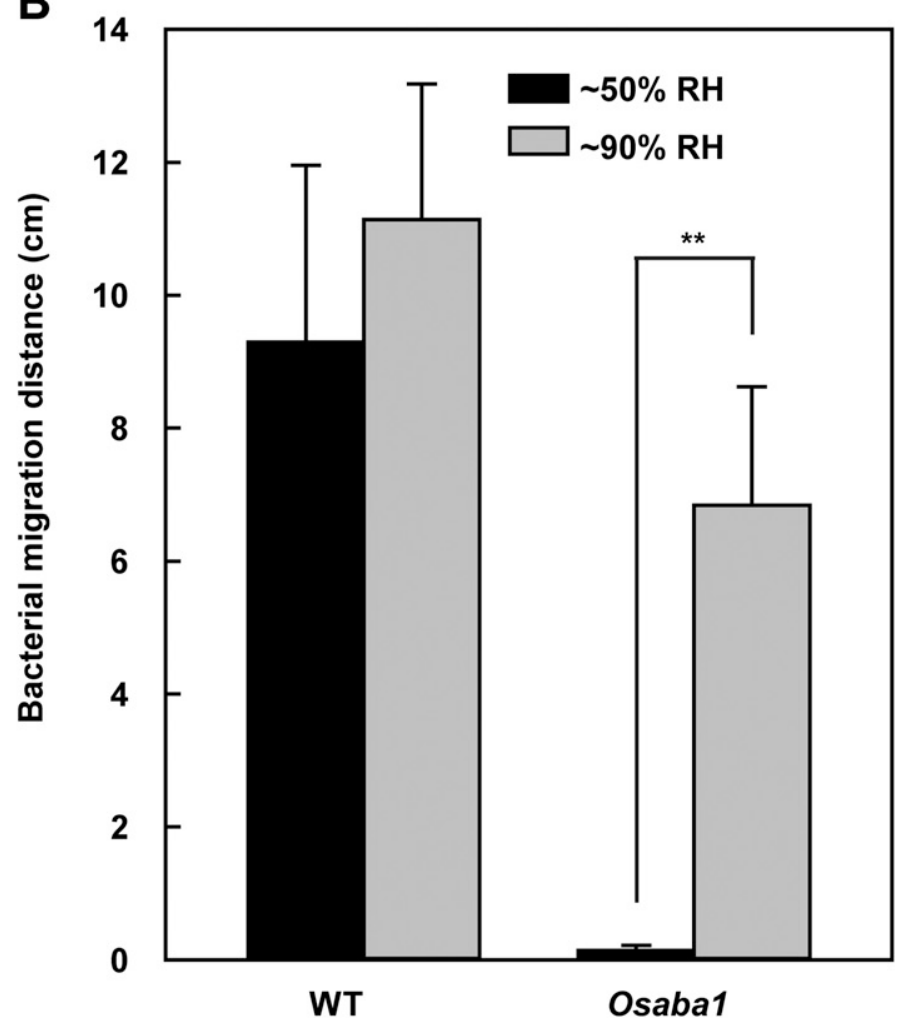

Fig. 4. Water status affects rice resistance against bacterial blight. A, Leaf water potentials of wild-type (WT) and Osabal plants. Values are means \pm standard deviation (SD), $n=3$, and asterisks (**) indicate $P<0.01$ ( $t$ test). B, High humidity reverses the resistance phenotype of $O$ sabal. WT and $O s a b a 1$ plants were leaf-clip inoculated with PXO99 ${ }_{\text {EGFP }}$ and then grown under indicated relative humidity $(\mathrm{RH})$. Migration distances of PXO99 $9_{\mathrm{EGFP}}$ were measured under a fluorescence stereo microscope at 4 days post leaf-clip inoculation. Values are means $\pm \mathrm{SD}, n \geq 10$, and asterisks $(* *)$ indicate $P<0.01(t$ test). 
signaling (Cao et al. 2011; Jiang et al. 2010; Xu et al. 2013). Interestingly, rice seedlings treated with the ABA biosynthesis inhibitor fluridone exhibited increased resistance to $X$. oryzae pv. oryzae, and the resistance appeared to be independent of $\mathrm{SA}$ (Xu et al. 2013). Our results also indicate that $X$. oryzae pv. oryzae resistance of the ABA-deficient mutant Osabal is unlikely due to activation of SA-dependent pathways. This was supported by our demonstration that Osabal/nahG plants still exhibited strong resistance. ABA plays a crucial role in controlling stomatal closure and, thereby, regulates water transpiration in plants (Daszkowska-Golec and Szarejko 2013). Stomatal conductance and water transpiration were greatly increased in the Osabal mutant (Fig. 2B). We provide several lines of evidence indicating that increased stomatal conductance and water transpiration lead to strong resistance to $X$. oryzae pv. oryzae. Therefore, ABA regulates plant disease resistance through controlling stomatal opening, in addition to its antagonistic role to SA.

Plants have a complex innate immune system that has coevolved with pathogens (Jones and Dangl 2006). Similar to Osabal, es 1-1, a rice mutant with constitutively half-open stomata, exhibits strong resistance to $X$. oryzae pv. oryzae. We also show that incremental changes in stomatal conductance induced by chemical and environmental cues result in enhanced resistance of rice to bacterial blight pathogens (Fig. 3). It has previously been shown that MAMP-triggered stomatal closure,
A

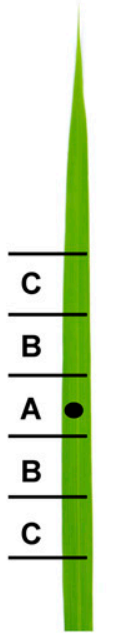

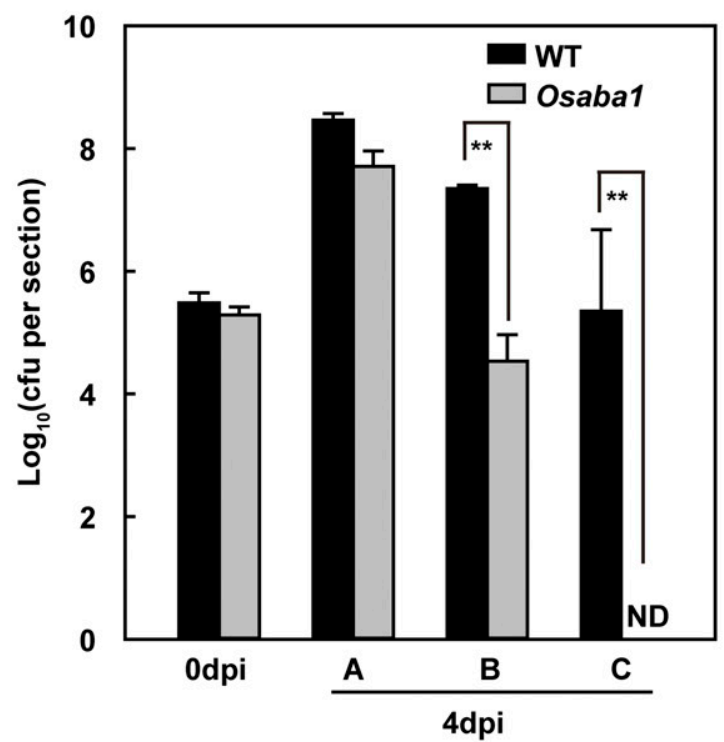

B
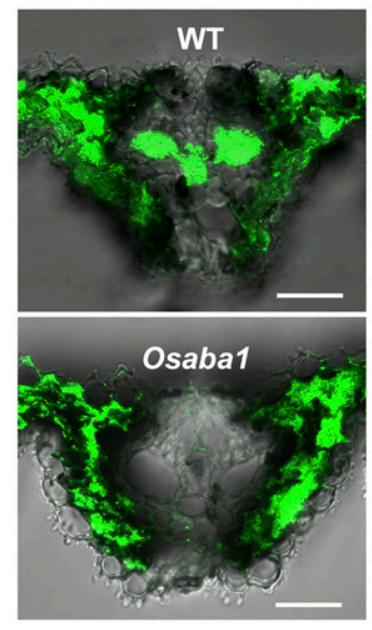

\footnotetext{
,
}
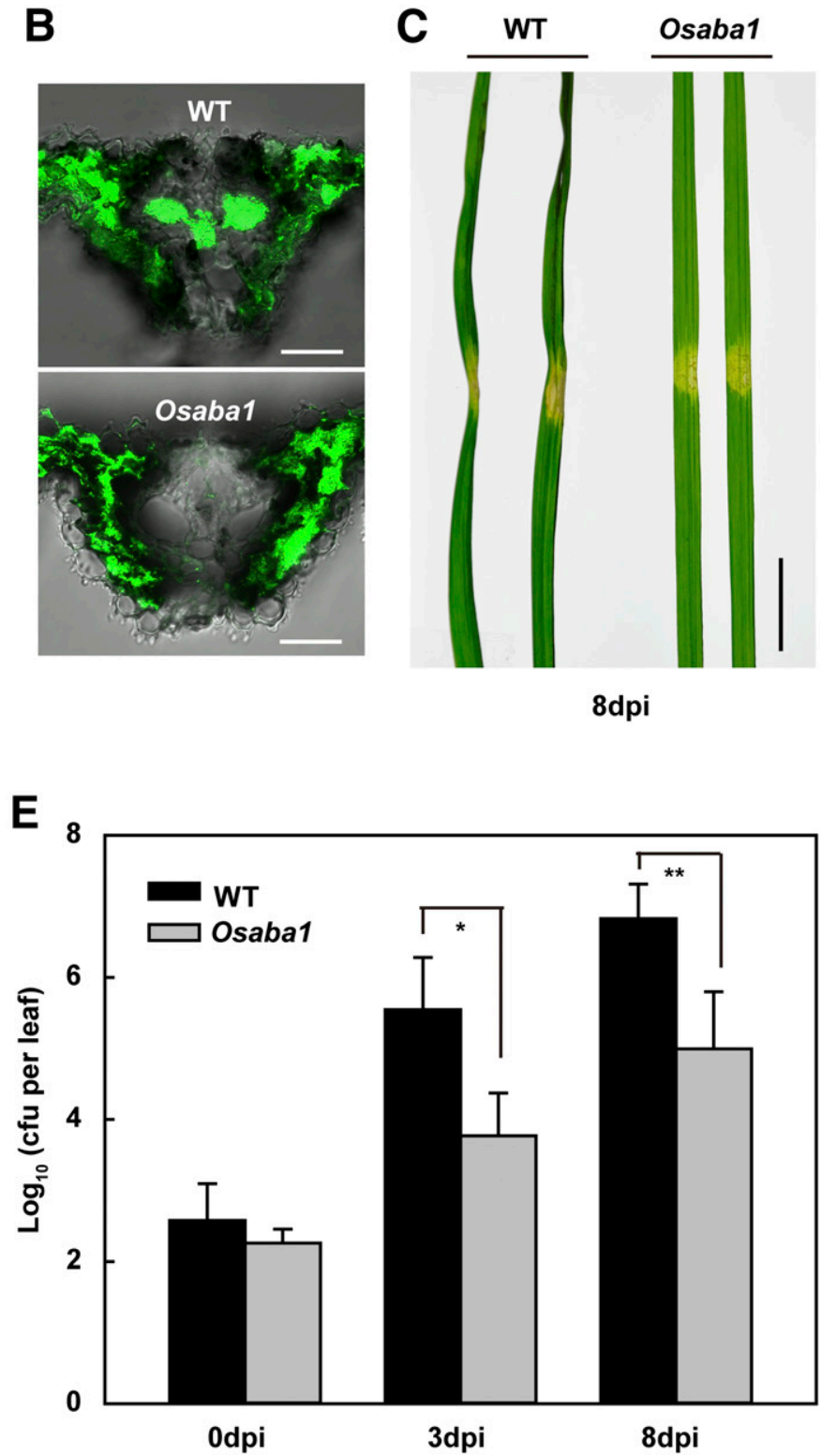

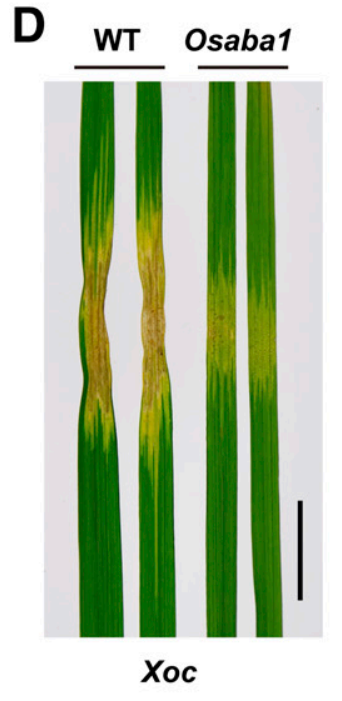

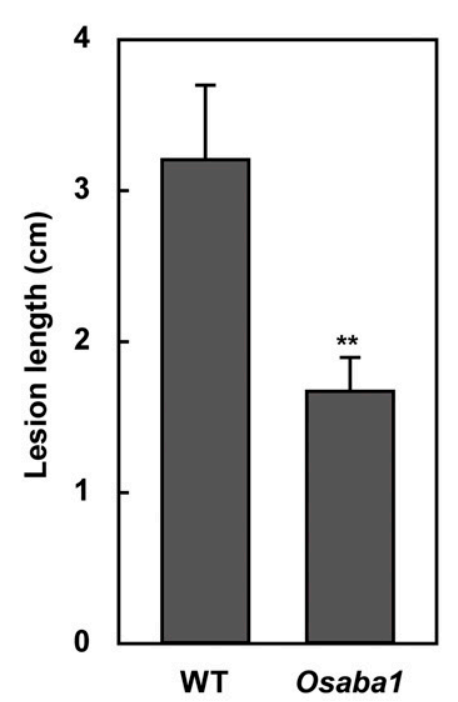

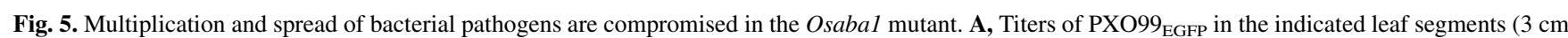
long each) at or around infiltration site of the wild-type (WT) and Osabal plants 4 days after infiltration. The black-filled circle in segment A indicates the infiltration site (left panel). ND $=$ not detected and dpi $=$ days postinoculation. Values are means \pm standard deviation $(\mathrm{SD}), n=3$, and asterisks $(* *)$ indicate $P<$ 0.01 ( $t$ test). B, Transverse sections of the leaf of WT and Osabal plants at a position near the junction of segments A and B as indicated in A. PXO99 EGFP colonization of leaf tissues was visualized using a confocal microscope 4 days after infiltration. Bar $=25 \mu \mathrm{m}$. C, Representative disease symptoms on leaves of WT and Osabal plants 8 days after infiltration inoculation with PXO99 ${ }_{\text {EGFP }}$ Representative leaves are shown. Bar $=1 \mathrm{~cm}$. D, Osabal plants exhibit strong resistance to Xanthomonas oryzae pv. oryzicola. Disease lesion development on WT and Osabal rice leaves 12 dpi. Photographs of representative leaves are shown (left panel). Bar $=1 \mathrm{~cm}$. Lesion lengths were measured and analyzed (right panel); values are means $\pm \mathrm{SD}, n \geq 15$, and asterisks $(* *)$ indicate $P<0.01$ ( $t$ test). E, Titers of $X$. oryzae pv. oryzicola in leaves of WT and Osabal plants after spray inoculation. Values are means $\pm \mathrm{SD}, n \geq 3$, and asterisks $(*$ and **) indicate $P<0.05$ and 0.01 , respectively ( $t$ test). 
known as stomatal defense (Melotto et al. 2017; Sawinski et al. 2013), represents a layer of immunity active during pathogen invasion. In turn, bacterial pathogens have evolved virulence factors or effectors that promote reopening of stomata (Melotto et al. 2006; Montillet et al. 2013). We show here that open stomata confer rice resistance to pathogenic bacteria. This resistance remained even when the bacterial pathogens were infiltration inoculated (Fig. 5), suggesting that (open) stomata in some circumstances confer an additional layer of immunity at the postinvasive level. The dual functions of stomata might ensure a robust plant immunity against bacterial pathogens.

$X$. oryzae pv. oryzae generally infects leaves through wounds or hydathodes, and spreads systemically through xylem (NiñoLiu et al. 2006). Thus, the kind of stomata noted above that physically limit pathogen entry may not be effective against $X$. oryzae pv. oryzae. If so, stomatal opening may affect disease resistance by other physiological processes. Stomatal conductance controls water transpiration and, thereby, modulates the
A

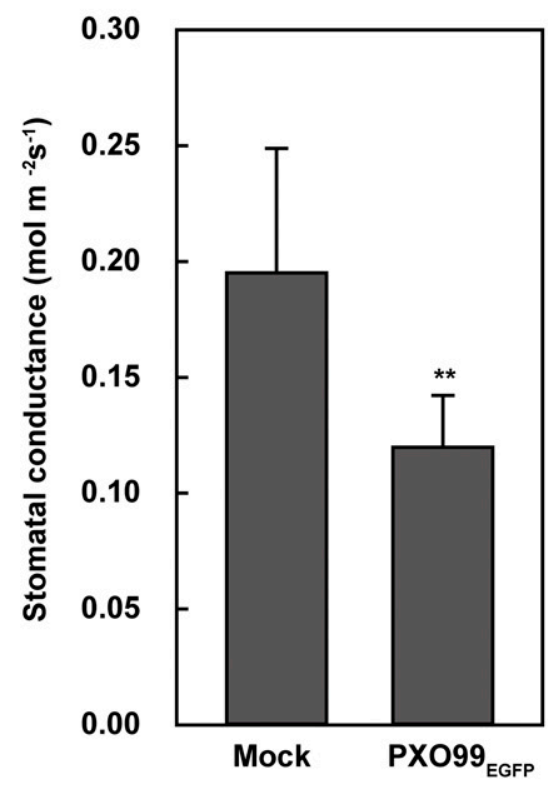

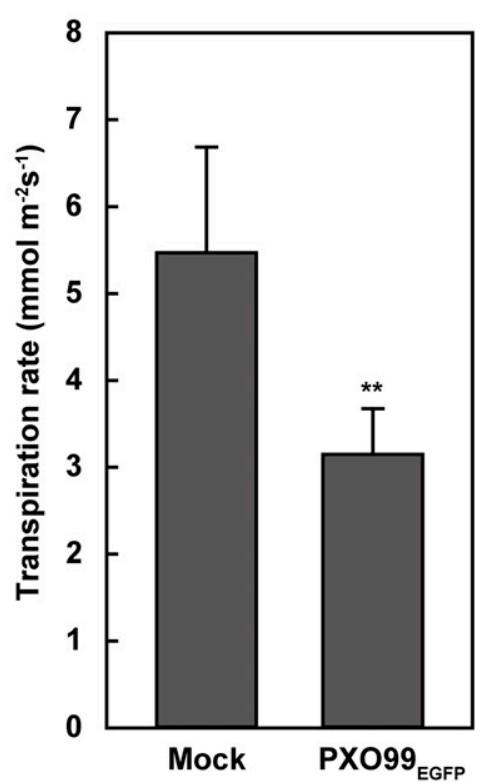

B

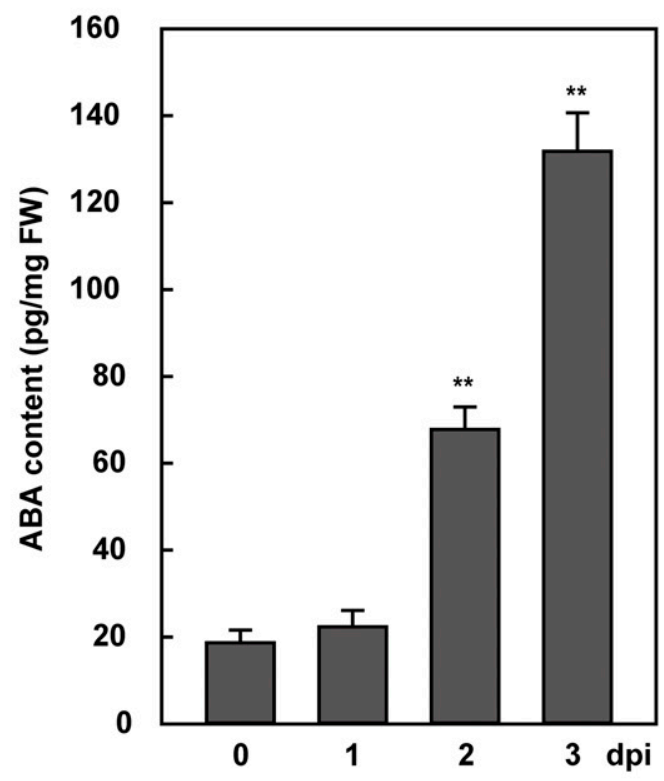

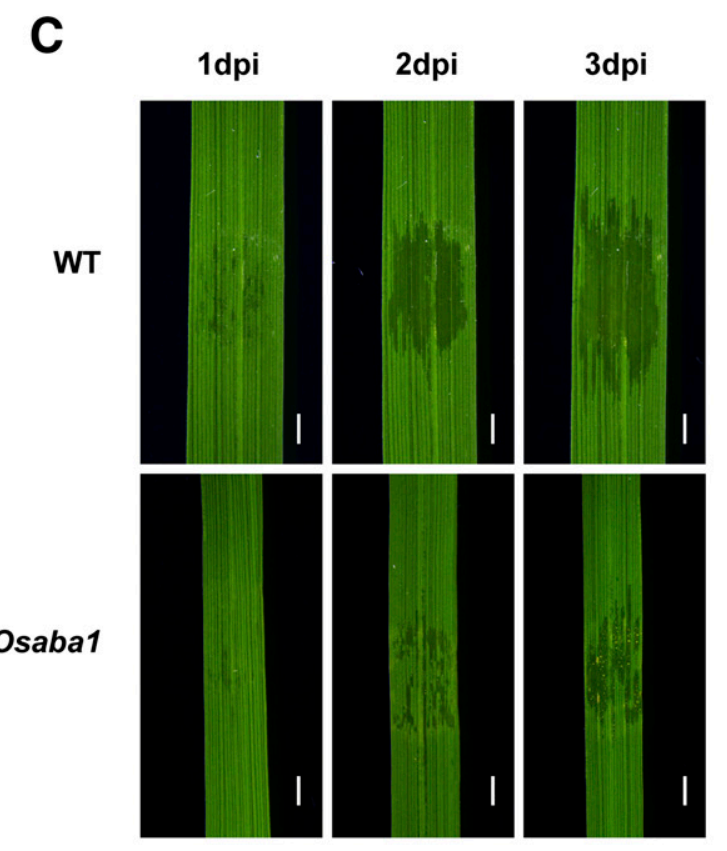

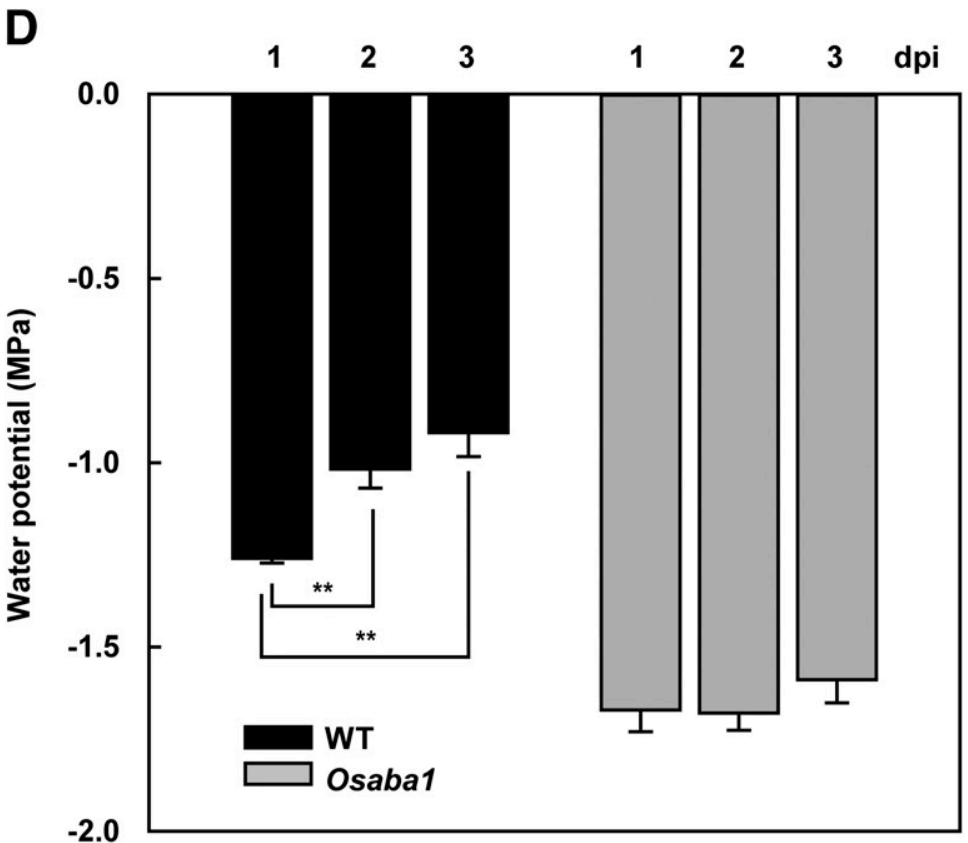

Fig. 6. Xanthomonas oryzae pv. oryzae modulates water status of rice leaves to facilitate infection. A, Stomatal conductance and transpiration rate of wild-type (WT) plants decrease upon $X$. oryzae pv. oryzae infection. Measurements were made on leaves 3 days post leaf-clip inoculation with suspension solution (mock) or $X$. oryzae pv. oryzae. Values are means \pm standard deviation (SD), $n \geq 8$, and asterisks (**) indicate $P<0.01$ ( $t$ test). B, $X$. oryzae pv. oryzae infection induces biosynthesis of abscisic acid (ABA) in rice. ABA contents of WT plants were measured at indicated time points after PXO99 infection. FW $=$ fresh weight. Values are means \pm SD and $n=3$. C, Water soaking develops on leaves of WT (upper panel) and Osabal (lower panel) infiltration inoculated with

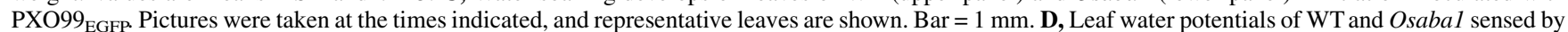
$X$. oryzae pv. oryzae cells as measured using a proU-inaZ fusion reporter system. Leaves were infiltration inoculated with PXO99 expressing proU-inaZ fusion. Measurements were taken at the indicated times. Values are means $\pm \mathrm{SD}, n=3$, and asterisks $(* *)$ indicate $P<0.01(t$ test). 
water status in leaves (Sheriff 1979). We show that water potential is lower in Osabal than wild-type plants both before and after $X$. oryzae pv. oryzae infection (Figs. 4 and 6). Growth under high ambient humidity reduces resistance to $X$. oryzae pv. oryzae in Osabal. Moreover, X. oryzae pv. oryzae actively modulates stomatal conductance and water potential of rice leaves (Fig. 6). Interestingly, it was previously shown that $X$. oryzae pv. oryzae infection reduced stomatal conductance and transpiration rates of leaves significantly more in a susceptible genotype than in resistant genotypes (Kumar et al. 2013). These data together support the idea that stomata modulate leaf water status to regulate disease resistance.

Leaf interior water status is also modulated by altering water flow from the xylem. Several studies revealed that limitation of water supply from vascular tissues occurs during both MAMP and ETI. Xylem conductivity is greatly reduced at leaf sites treated with MAMPs or at sites undergoing the hypersensitive response (HR) (Freeman and Beattie 2009; Oh and Collmer 2005; Wright and Beattie 2004). Interestingly, high relative humidity suppresses HR development in plants (Hammond-Kosack et al. 1996; May et al. 1996; Zhou et al. 2004). This supports an essential role of leaf water status in plant immunity. Moreover, bacterial effectors may target other host cellular compartments to create an aqueous living space (Schwartz et al. 2017; Xin et al. 2016), supporting the idea that there exist ways other than stomata for a host to ration water during interactions with bacterial pathogens.

In summary, our work reveals that leaf water status controlled by stomata plays an essential role in rice resistance against bacterial pathogens. Interestingly, this resistance appears to be broad spectrum. Therefore, modification of stomatal opening and leaf water status may represent novel strategies to improve plant disease resistance.

\section{MATERIALS AND METHODS}

Plant materials and growth conditions.

Rice ( $O$. sativa subsp. japonica 'Nipponbare') plants were grown in a field paddy in Beijing from May to October of each year for genetic analyses and seed set. For disease resistance assays, rice seedlings were grown in a chamber with a light intensity of $110 \mu \mathrm{mol} \mathrm{m} \mathrm{m}^{-2} \mathrm{~s}^{-1}$ under a cycle of $13 \mathrm{~h}$ of light at $28^{\circ} \mathrm{C}$ and $11 \mathrm{~h}$ of darkness at $26^{\circ} \mathrm{C}$, with $50 \%$ relative humidity, unless otherwise indicated.

\section{Chemical treatments.}

Working solutions of 5, 10, and $100 \mu \mathrm{M}$ ABA (Phyto Technology Laboratories); $100 \mu \mathrm{M}$ atrazine (Aladdin-reagent.com); and $10 \mu \mathrm{M}$ fusicoccin (Sigma-Aldrich.com) were prepared in water containing $0.02 \%$ ( $\mathrm{vol} / \mathrm{vol}$ ) Tween 20 . Wilt-Pruf (WiltPruf Products, Inc.) was diluted $1: 80$ in water to make a working solution. All chemicals were applied by spraying with a vaporizer until leaves were finely coated.

\section{ABA and SA content measurement.}

For each sample, leaf tissue (fresh weight) was collected from plants at the six-leaf stage, weighed, and frozen in liquid nitrogen. ABA extraction and content measurement were performed as previously described (Fu et al. 2012). Total SA contents of rice leaves were determined as previously described (Liu et al. 2012).

\section{Bacterial pathogens.}

X. oryzae pv. oryzae strains were PX099, PXO61, PX086, PXO71, PXO112, and PXO145 from the Philippines and Zhe173 from China. The $X$. oryzae pv. oryzicola strain used was RS105. Strains were grown in peptone sucrose (PS) medium
(Tsuchiya et al. 1982) or on peptone sucrose agar (PSA) plates. PXO99 expressing green fluorescent protein (PXO99 EGFP) was $_{\text {a }}$ generated as previously reported (Han et al. 2008). A fragment encoding EGFP was excised from the pEGFP vector (Clontech) by $P s t \mathrm{I}$ and EcoRI digestion, subcloned into pHM1 (Wang et al. 2011), and transformed into PXO99 by electroporation. Positive clones were obtained on PSA containing spectinomycin $(100 \mu \mathrm{g} / \mathrm{ml})$, and confirmed by colony PCR and confocal observation.

\section{Pathogen inoculation and virulence assay.}

The two most recent fully expanded leaves of rice plants at the six-leaf stage were inoculated with $X$. oryzae pv. oryzae by leaf-tip clipping or at the four-leaf stage by syringe infiltration methods, as described (Yang and Bogdanove 2013). Disease symptoms were scored by measuring lesion lengths. To quantify bacterial growth in rice leaves, infected leaves were detached and surface sterilized with $75 \%$ ethanol, then homogenized in $3 \mathrm{ml}$ of sterile distilled water with a mortar and pestle. Extracts were diluted serially and plated on PSA containing spectinomycin. Plates were incubated at $28^{\circ} \mathrm{C}$ for 3 days. Colonies were then counted and the mean number in at least three repeats was calculated.

For experiments with rice treated with chemicals and constant light, a shorter duration ( 3 to 4 days instead of 12 days) of $X$. oryzae pv. oryzae infection was adopted. To facilitate the observation of disease development, the rice plants were leafclip inoculated with PXO99 ${ }_{\text {EGFP. }}$ Disease development was detected under a fluorescence microscope by observing GFP fluorescence in the veins. Disease symptoms were scored by measuring the distance migrated by PXO99 $9_{\text {EGFP }}$ along the vascular system.

$X$. oryzae pv. oryzicola was inoculated on leaves of rice seedlings by syringe infiltration methods, as previously described (Yang and Bogdanove 2013). For spray inoculation, $X$. oryzae pv. oryzicola was suspended in sterile $10 \mathrm{mM} \mathrm{MgCl}_{2}$ with $0.1 \%$ Tween-20 to an optical density at $600 \mathrm{~nm}$ of 0.3 . Following inoculation, plants were maintained under high humidity ( 90 to $100 \%$ ) for $3 \mathrm{~h}$ before moving them to a growth chamber with $50 \%$ relative humidity. To quantify bacterial growth in rice leaves, 10 -cm-long infected leaf segments were detached, surface sterilized in $75 \%$ ethanol, then ground in sterile water. CFU were determined by serial dilutions and plating on PSA plates containing rifampicin.

\section{Vector construction and rice transformation.}

To overexpress OsABA8oxl, the full-length cDNA was amplified and cloned into the binary vector pCAMBIA2300 and driven by the maize Ubiquitin 1 promoter (Gao et al. 2014). To generate the RNAi constructs for $O s A B A 2$ and $O s A B A 3$, genespecific fragments of the coding regions of approximately $300 \mathrm{bp}$ were amplified and inserted into pTCK303 (Wang et al. 2004) in both sense and antisense directions. Primer sequences used for vector construction are listed in Supplementary Table S1. The constructs were introduced into Agrobacterium tumefaciens AGL1 by electroporation, then transformed into rice callus, as previously described (Hiei et al. 1994).

\section{RT-PCR and quantitative RT-PCR.}

Total RNA was extracted from rice leaves with TRIzol reagent (Invitrogen). Each RNA sample $(2 \mu \mathrm{g})$ was treated with DNase I (Invitrogen) and reverse transcribed with M-MLV RT (Takara) according to the manufacturer's instructions. For semiquantitative RT-PCR, PCR parameters were as follows: preincubation at $94^{\circ} \mathrm{C}$ for $3 \mathrm{~min}$, followed by 25 or 28 cycles of $94^{\circ} \mathrm{C}$ for $30 \mathrm{~s}, 60^{\circ} \mathrm{C}$ for $30 \mathrm{~s}$, and $72^{\circ} \mathrm{C}$ for $1 \mathrm{~min}$. Quantitative (q)RT-PCR was performed on a Bio-Rad CFX96 (Bio-Rad 
Laboratories) using TakaRa SYBR Premix Ex Taq II following the manufacturer's instructions. qRT-PCR was performed in triplicate for each sample. Normalized expression levels were calculated using Ubiqitin5 as an internal reference gene (Jain et al. 2006) with CFX Manager Software (Bio-Rad) and the $2^{-\Delta \Delta C(\mathrm{t})}$ method.

\section{Confocal microscopy and fluorescence stereomicroscopy.}

To visualize $X$. oryzae pv. oryzae inside leaves, thin transverse sections $(0.1 \mathrm{~mm})$ of rice leaves were prepared as previously described (Han et al. 2008). Confocal imaging used a Leica TCS SP8 with excitation at $488 \mathrm{~nm}$ and emission at 500 to $550 \mathrm{~nm}$ for EGFP. A fluorescence stereomicroscope (Leica M205 FA) was used to observe PXO99 ${ }_{\text {EGFP }}$ colonization in leaves. Leaf segments were mounted on a microscope slide, and photographs were taken using LAS V4.2 software.

\section{Stomatal conductance and transpiration rate measurements.}

Stomatal conductance and transpiration rate were measured using a portable photosynthesis system (Model LI-6400XT; LiCor Inc.) with a leaf chamber $(2$ by $3 \mathrm{~cm})$ supplied with a redblue LED light source. Measurements were made inside the growth chamber to minimize environmental noise. Measurement parameters were $\mathrm{CO}_{2}$ at $400 \mu \mathrm{mol} \mathrm{mol}^{-1}$ and photosynthetic photon flux density of $200 \mu \mathrm{mol} \mathrm{m} \mathrm{m}^{-2}$. The light source was turned off when measurements were made in the dark.

\section{Water potential measurement.}

Water potentials were measured with a WP4-T Dewpoint Potential Meter (Decagon Devices Inc.) under continuous mode. Leaves were cut into segments and placed in a sample cup to fully cover the bottom of the cup. Each measurement was an average of six independent repeats.

\section{Measuring the water potential sensed}

by $X$. oryzae pv. oryzae with proU-inaZ fusion.

The plasmid pPProIce containing a proU-inaZ fusion was introduced into PXO99. Measurement of ice nucleation activity (INA) was performed as previously described, with minor modifications (Wright and Beattie 2004). The INA of $X$. oryzae pv. oryzae cells recovered from plants was evaluated by homogenizing infected leaves, subjecting dilutions made with PS medium, and measuring by a droplet-freezing assay at $-9^{\circ} \mathrm{C}$. The water potential sensed by $X$. oryzae pv. oryzae cells was calculated using the relations between INA and water potential that were established by growing $X$. oryzae pv. oryzae cells on solid medium supplied with various concentrations of $\mathrm{NaCl}$.

\section{ACKNOWLEDGMENTS}

We thank Q. Qian, C. Chu, Y. Rao, and J. Fang for providing rice mutants; G. A. Beattie for providing plasmids pPProIce and pPNptIce; W. Qian and G. Chen for providing the X. oryzae pv. oryzae strains; and J. Mundy for critical reading of the manuscript.

\section{LITERATURE CITED}

Asselbergh, B., De Vleesschauwer, D., and Höfte, M. 2008. Global switches and fine-tuning-ABA modulates plant pathogen defense. Mol. Plant-Microbe Interact. 21:709-719.

Bajaj, S., and Mohanty, A. 2005. Recent advances in rice biotechnology-towards genetically superior transgenic rice. Plant Biotechnol. J. 3: 275-307.

Bashan, Y. 1987. Mechanisms of symptom production by foliar bacterial pathogens. Phytoparasitica 15:197-223.

Beattie, G. A. 2011. Water relations in the interaction of foliar bacterial pathogens with plants. Annu. Rev. Phytopathol. 49:533-555.
Beattie, G. A. 2016. A war over water when bacteria invade leaves. Nature 539:506-507.

Beattie, G. A., and Lindow, S. E. 1995. The secret life of foliar bacterial pathogens on leaves. Annu. Rev. Phytopathol. 33:145-172.

Beattie, G. A., and Lindow, S. E. 1999. Bacterial colonization of leaves: A spectrum of strategies. Phytopathology 89:353-359.

Cao, F. Y., Yoshioka, K., and Desveaux, D. 2011. The roles of ABA in plant-pathogen interactions. J. Plant Res. 124:489-499.

Chavarria, G., and dos Santos, H. P. 2012. Plant Water Relations: Absorption, Transport and Control Mechanisms. Pages105-132 in: Advances in Selected Plant Physiology Aspects. G. Montanaro and B. Dichio, eds. Online publication. InTech. https://www.intechopen.com/books/advances-in-selected-plant-physiology-aspects/plant-water-relations-absorption-transport-and-control-mechanisms

Chen, X., and Ronald, P. C. 2011. Innate immunity in rice. Trends Plant Sci. 16:451-459.

Daszkowska-Golec, A., and Szarejko, I. 2013. Open or close the gate stomata action under the control of phytohormones in drought stress conditions. Front. Plant Sci. 4:138.

De Vleesschauwer, D., Gheysen, G., and Höfte, M. 2013. Hormone defense networking in rice: Tales from a different world. Trends Plant Sci. 18: 555-565.

Fang, J., and Chu, C. 2008. Abscisic acid and the pre-harvest sprouting in cereals. Plant Signal. Behav. 3:1046-1048.

Fatima, U., and Senthil-Kumar, M. 2015. Plant and pathogen nutrient acquisition strategies. Front. Plant Sci. 6:750.

Freeman, B. C., and Beattie, G. A. 2009. Bacterial growth restriction during host resistance to Pseudomonas syringae is associated with leaf water loss and localized cessation of vascular activity in Arabidopsis thaliana. Mol. Plant-Microbe Interact. 22:857-867.

Fu, J., Chu, J., Sun, X., Wang, J., and Yan, C. 2012. Simple, rapid, and simultaneous assay of multiple carboxyl containing phytohormones in wounded tomatoes by UPLC-MS/MS using single SPE purification and isotope dilution. Anal. Sci. 28:1081-1087.

Gao, S., Fang, J., Xu, F., Wang, W., Sun, X., Chu, J., Cai, B., Feng, Y., and Chu, C. 2014. CYTOKININ OXIDASE/DEHYDROGENASE4 integrates cytokinin and auxin signaling to control rice crown root formation. Plant Physiol. 165:1035-1046.

Hammond-Kosack, K. E., Silverman, P., Raskin, I., and Jones, J. D. G. 1996. Race-specific elicitors of Cladosporium fulvum induce changes in cell morphology and the synthesis of ethylene and salicylic acid in tomato plants carrying the corresponding $\mathrm{Cf}$ disease resistance gene. Plant Physiol. 110:1381-1394.

Han, S.-W., Park, C.-J., Lee, S.-W., and Ronald, P. C. 2008. An efficient method for visualization and growth of fluorescent Xanthomonas oryzae pv. oryzae in planta. BMC Microbiol. 8:164.

Hiei, Y., Ohta, S., Komari, T., and Kumashiro, T. 1994. Efficient transformation of rice (Oryza sativa L.) mediated by Agrobacterium and sequence analysis of the boundaries of the T-DNA. Plant J. 6: 271-282.

Jachetta, J. J., Appleby, A. P., and Boersma, L. 1986. Apoplastic and symplastic pathways of atrazine and glyphosate transport in shoots of seedling sunflower. Plant Physiol. 82:1000-1007.

Jain, M., Nijhawan, A., Tyagi, A. K., and Khurana, J. P. 2006. Validation of housekeeping genes as internal control for studying gene expression in rice by quantitative real-time PCR. Biochem. Biophys. Res. Commun. 345:646-651.

Jiang, C. J., Shimono, M., Sugano, S., Kojima, M., Yazawa, K., Yoshida, R., Inoue, H., Hayashi, N., Sakakibara, H., and Takatsuji, H. 2010. Abscisic acid interacts antagonistically with salicylic acid signaling pathway in rice-Magnaporthe grisea interaction. Mol. Plant-Microbe Interact. 23: 791-798.

Jones, J. D. G., and Dangl, J. L. 2006. The plant immune system. Nature 444:323-329.

Kauffman, H. E., Reddy, A. P. K., Hsieh, S. P. V., and Marca, S. D. 1973. An improved technique for evaluation of resistance of rice varieties to Xanthomonas oryzae. Plant Dis. Rep. 57:537-541.

Kim, T. H., Böhmer, M., Hu, H., Nishimura, N., and Schroeder, J. I. 2010. Guard cell signal transduction network: Advances in understanding abscisic acid, $\mathrm{CO}_{2}$, and $\mathrm{Ca}^{2+}$ signaling. Annu. Rev. Plant Biol. 61: 561-591.

Kinoshita, T., Doi, M., Suetsugu, N., Kagawa, T., Wada, M., and Shimazaki, K. 2001. Phot 1 and phot 2 mediate blue light regulation of stomatal opening. Nature 414:656-660.

Kumar, A., Guha, A., Bimolata, W., Reddy, A. R., Laha, G. S., Sundaram, R. M., Pandey, M. K., and Ghazi, I. A. 2013. Leaf gas exchange physiology in rice genotypes infected with bacterial blight: An attempt to 
link photosynthesis with disease severity and rice yield. Aust. J. Crop Sci. 7:32-39

Le Fevre, R., Evangelisti, E., Rey, T., and Schornack, S. 2015. Modulation of host cell biology by plant pathogenic microbes. Annu. Rev. Cell Dev. Biol. 31:201-229.

Lindow, S. E., and Brandl, M. T. 2003. Microbiology of the phyllosphere. Appl. Environ. Microbiol. 69:1875-1883.

Liu, H., Li, X., Xiao, J., and Wang, S. 2012. A convenient method for simultaneous quantification of multiple phytohormones and metabolites: Application in study of rice-bacterium interaction. Plant Methods 8:2.

Lozano-Durán, R., Bourdais, G., He, S. Y., and Robatzek, S. 2014. The bacterial effector HopM1 suppresses PAMP-triggered oxidative burst and stomatal immunity. New Phytol. 202:259-269.

May, M. J., Hammond-Kosack, K. E., and Jones, J. D. G. 1996. Involvement of reactive oxygen species, glutathione metabolism, and lipid peroxidation in the Cf-gene-dependent defense response of tomato cotyledons induced by race-specific elicitors of Cladosporium fulvum. Plant Physiol. 110:1367-1379.

Melotto, M., Underwood, W., and He, S. Y. 2008. Role of stomata in plant innate immunity and foliar bacterial diseases. Annu. Rev. Phytopathol. 46:101-122.

Melotto, M., Underwood, W., Koczan, J., Nomura, K., and He, S. Y. 2006. Plant stomata function in innate immunity against bacterial invasion. Cell 126:969-980.

Melotto, M., Zhang, L., Oblessuc, P. R., and He, S. Y. 2017. Stomatal defense a decade later. Plant Physiol. 174:561-571.

Merilo, E., Yarmolinsky, D., Jalakas, P., Parik, H., Tulva, I., Rasulov, B., Kilk, K., and Kollist, H. 2018. Stomatal VPD response: There is more to the story than ABA. Plant Physiol. 176:851-864.

Mittelheuser, C. J., and Van Steveninck, R. F. M. 1969. Stomatal closure and inhibition of transpiration induced by (RS)-abscisic acid. Nature 221:281-282.

Montillet, J. L., Leonhardt, N., Mondy, S., Tranchimand, S., Rumeau, D., Boudsocq, M., Garcia, A. V., Douki, T., Bigeard, J., Laurière, C., Chevalier, A., Castresana, C., and Hirt, H. 2013. An abscisic acidindependent oxylipin pathway controls stomatal closure and immune defense in Arabidopsis. PLoS Biol. 11:e1001513.

Niño-Liu, D. O., Ronald, P. C., and Bogdanove, A. J. 2006. Xanthomonas oryzae pathovars: Model pathogens of a model crop. Mol. Plant Pathol. 7:303-324.

Noda, T., and Kaku, H. 1999. Growth of Xanthomonas oryzae pv. oryzae in planta and in guttation fluid of rice. Ann. Phytopathol. Soc. Jpn. 65:9-14.

Oh, H.-S., and Collmer, A. 2005. Basal resistance against bacteria in Nicotiana benthamiana leaves is accompanied by reduced vascular staining and suppressed by multiple Pseudomonas syringae type III secretion system effector proteins. Plant J. 44:348-359.

Powles, S. B., and Yu, Q. 2010. Evolution in action: Plants resistant to herbicides. Annu. Rev. Plant Biol. 61:317-347.

Rao, Y., Yang, Y., Xu, J., Li, X., Leng, Y., Dai, L., Huang, L., Shao, G., Ren, D., Hu, J., Guo, L., Pan, J., and Zeng, D. 2015. EARLY SENESCENCE1 encodes a SCAR-LIKE PROTEIN2 that affects water loss in rice. Plant Physiol. 169:1225-1239.

Reimers, P. J., and Leach, J. E. 1991. Race-specific resistance to Xanthomonas oryzae pv. oryzae conferred by bacterial-blight resistance gene $\mathrm{Xa}-10$ in rice (Oryza sativa) involves accumulation of a lignin-like substance in host tissues. Physiol. Mol. Plant Pathol. 38:39-55.

Saika, H., Okamoto, M., Miyoshi, K., Kushiro, T., Shinoda, S., Jikumaru, Y., Fujimoto, M., Arikawa, T., Takahashi, H., Ando, M., Arimura, S., Miyao, A., Hirochika, H., Kamiya, Y., Tsutsumi, N., Nambara, E., and Nakazono, M. 2007. Ethylene promotes submergence-induced expression of OsABA8ox1, a gene that encodes ABA 8'-hydroxylase in rice. Plant Cell Physiol. 48:287-298.

Sanabria, N., Goring, D., Nürnberger, T., and Dubery, I. 2008. Self/nonself perception and recognition mechanisms in plants: A comparison of selfincompatibility and innate immunity. New Phytol. 178:503-514.

Sawinski, K., Mersmann, S., Robatzek, S., and Böhmer, M. 2013. Guarding the green: Pathways to stomatal immunity. Mol. Plant-Microbe Interact. 26:626-632.

Scholthof, K. B. G. 2007. The disease triangle: Pathogens, the environment and society. Nat. Rev. Microbiol. 5:152-156.

Schornack, S., Minsavage, G. V., Stall, R. E., Jones, J. B., and Lahaye, T. 2008. Characterization of AvrHah1, a novel AvrBs3-like effector from Xanthomonas gardneri with virulence and avirulence activity. New Phytol. 179:546-556.

Schulze, E. D., and Hall, A. E. 1982. Stomatal responses, water loss and $\mathrm{CO} 2$ assimilation rates of plants in contrasting environments. Pages 181-230 in: Physiological Plant Ecology II. Encyclopedia of Plant Physiology (New Series), Vol. 12. O. L. Lange, P. S. Nobel, C. B. Osmond, and H. Ziegler, eds. Springer, Berlin, Heidelberg.
Schwartz, A. R., Morbitzer, R., Lahaye, T., and Staskawicz, B. J. 2017. TALE-induced bHLH transcription factors that activate a pectate lyase contribute to water soaking in bacterial spot of tomato. Proc. Natl. Acad. Sci. U.S.A. 114:E897-E903.

Sheriff, D. W. 1979. Stomatal aperture and the sensing of the environment by guard cells. Plant Cell Environ. 2:15-22.

Silverman, P., Seskar, M., Kanter, D., Schweizer, P., Metraux, J. P., and Raskin, I. 1995. Salicylic acid in rice (biosynthesis, conjugation, and possible role). Plant Physiol. 108:633-639.

Sun, Z., Jin, X., Albert, R., and Assmann, S. M. 2014. Multi-level modeling of light-induced stomatal opening offers new insights into its regulation by drought. PLOS Comput. Biol. 10:e1003930.

Tang, J., Zhu, X., Wang, Y., Liu, L., Xu, B., Li, F., Fang, J., and Chu, C. 2011. Semi-dominant mutations in the CC-NB-LRR-type R gene, NLS1, lead to constitutive activation of defense responses in rice. Plant J. 66: 996-1007.

Tsuchiya, K., Mew, T. W., and Wakimoto, S. 1982. Bacteriological and pathological characteristics of wild types and induced mutants of Xanthomonas campestris pv. oryzae. Phytopathology 72:43-46.

Turner, N. C. 1972. K+ uptake of guard cells stimulated by fusicoccin. Nature 235:341-342.

Tuteja, N. 2007. Abscisic acid and abiotic stress signaling. Plant Signal. Behav. 2:135-138.

Underwood, W., Melotto, M., and He, S. Y. 2007. Role of plant stomata in bacterial invasion. Cell. Microbiol. 9:1621-1629.

Walters, D. R. 2006. Disguising the leaf surface: The use of leaf coatings for plant disease control. Eur. J. Plant Pathol. 114:255-260.

Wang, L., Zhang, L., Geng, Y., Xi, W., Fang, R., and Jia, Y. 2011. XerR, a negative regulator of $\mathrm{XccR}$ in Xanthomonas campestris pv. campestris, relieves its repressor function in planta. Cell Res. 21:1131-1142.

Wang, M., Chen, C., Xu, Y. Y., Jiang, R. X., Han, Y., Xu, Z. H., and Chong, K. 2004. A practical vector for efficient knockdown of gene expression in rice (Oryza sativa L.). Plant Mol. Biol. Rep. 22:409-417.

Webb, K. M., Garcia, E., Vera Cruz, C. M., and Leach, J. E. 2010. Influence of rice development on the function of bacterial blight resistance genes. Eur. J. Plant Pathol. 128:399-407.

Wilson, M., Hirano, S. S., and Lindow, S. E. 1999. Location and survival of leaf-associated bacteria in relation to pathogenicity and potential for growth within the leaf. Appl. Environ. Microbiol. 65:1435-1443.

Wright, C. A., and Beattie, G. A. 2004. Pseudomonas syringae pv. tomato cells encounter inhibitory levels of water stress during the hypersensitive response of Arabidopsis thaliana. Proc. Natl. Acad. Sci. U.S.A. 101:3269-3274.

Xin, X.-F., Nomura, K., Aung, K., Velásquez, A. C., Yao, J., Boutrot, F., Chang, J. H., Zipfel, C., and He, S. Y. 2016. Bacteria establish an aqueous living space in plants crucial for virulence. Nature 539:524-529.

Xu, J., Audenaert, K., Hofte, M., and De Vleesschauwer, D. 2013. Abscisic acid promotes susceptibility to the rice leaf blight pathogen Xanthomonas oryzae pv. oryzae by Suppressing Salicylic Acid-Mediated Defenses. PLoS One 8:e67413.

$\mathrm{Xu}, \mathrm{Z}$., and Zhou, G. 2008. Responses of leaf stomatal density to water status and its relationship with photosynthesis in a grass. J. Exp. Bot. 59: 3317-3325.

Yang, B., and Bogdanove, A. 2013. Inoculation and virulence assay for bacterial blight and bacterial leaf streak of rice. Methods Mol. Biol. 956: 249-255.

Yazawa, K., Jiang, C.-J., Kojima, M., Sakakibara, H., and Takatsuji, H. 2012. Reduction of abscisic acid levels or inhibition of abscisic acid signaling in rice during the early phase of Magnaporthe oryzae infection decreases its susceptibility to the fungus. Physiol. Mol. Plant Pathol. 78: $1-7$.

Young, J. M. 1974. Development of bacterial populations in vivo in relation to plant pathogenicity. N. Z. J. Agric. Res. 17:105-113.

Zeiger, E. 1983. The biology of stomatal guard cells. Annu. Rev. Plant Physiol. 34:441-474.

Zhang, H., and Wang, S. 2013. Rice versus Xanthomonas oryzae pv. oryzae: A unique pathosystem. Curr. Opin. Plant Biol. 16:188-195.

Zhou, F., Menke, F. L. H., Yoshioka, K., Moder, W., Shirano, Y., and Klessig, D. F. 2004. High humidity suppresses ssi4-mediated cell death and disease resistance upstream of MAP kinase activation, $\mathrm{H} 2 \mathrm{O} 2$ production and defense gene expression. Plant J. 39:920-932.

Zhu, M., Dai, S., and Chen, S. 2012. The stomata frontline of plant interaction with the environment-perspectives from hormone regulation. Front. Biol. 7:96-112.

\section{AUTHOR-RECOMMENDED INTERNET RESOURCE}

Rice Genome Annotation Project: http://rice.plantbiology.msu.edu/ 